\title{
Study on the Structure Model of Water Molecule and the Reasons of Formation of Some Characteristics of Liquid \& Solid Water
}

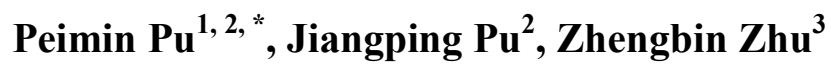 \\ ${ }^{1}$ Nanjing Institute of Geography \& Limnology, Chinese Academy of Sciences, Nanjing, China \\ ${ }^{2}$ Cloud Water Engineering Inc. (CWEI), Nanjing, China \\ ${ }^{3}$ Faculty of Engineering, Computer and Mathematical Sciences, University of Adelaide, Adelaide, South Australia, Australia
}

\section{Email address:}

pupm2@qq.com (Peimin Pu), jumpy@126.com (Jiangping Pu), robinzhu81@hotmail.com (Zhengbin Zhu)

${ }^{*}$ Corresponding author

\section{To cite this article:}

Peimin Pu, Jiangping Pu, Zhengbin Zhu. Study on the Structure Model of Water Molecule and the Reasons of Formation of Some Characteristics of Liquid \& Solid Water. American Journal of Modern Physics. Vol. 9, No. 2, 2020, pp. 11-27.

doi: 10.11648/j.ajmp.20200902.11

Received: April 14, 2020; Accepted: May 22, 2020; Published: June 17, 2020

\begin{abstract}
A model for water $\left(\mathrm{H}_{2} \mathrm{O}\right)$ molecule, the structure of ice, snow and liquid water were presented, and the reasons of formation of their specific characteristics were modeled in good coincidence with observed data. (1) A stable quasi rigid molecule structure may be constructed by dominant trajectories of electrons round and between the H-O-H nucleus according with the laws of Columb's force and Kepler's movement rule. The core of the water molecule is a isosceles triangle with ratio of distances between nucleus: $(\mathrm{H}-\mathrm{H})^{2} /(\mathrm{H}-\mathrm{O})^{2}=2.5$, which would be surrounded by moving electrons and form an equilateral triangular pyramid (ETP Model) with 2 pairs of "+/." electricity endpoints and edge length of $0.48017 \mathrm{~nm}$. (2) The "+/." endpoint of a water molecule may attract other "-/+" endpoint in distance of less than $0.27 \mathrm{~nm}$. A molecule may joints other molecule to have all their 4 planes parallel each other and the 6 molecules may joint as a hexagon loop with a common plane and then these loops may similarly be formed for each plane of the pyramid and extend to whole space and form the water ice structure with Zigzag Hexagon Tunnel-Vacancy System (ZHTVS Model) with porosity of $\geq 2.28$. (3) A "sheet model" of desublimation like the snowflake is more possible phenomenon below $0^{\circ} \mathrm{C}$ in air, possessing the self-similarity with the hexagon-sexangle-six needle forms. (4) The liquid water has the same structure of the solid ice, but because there is $1 / 11$ possibility to have an appearance of double electrons at one endpoint of the pyramid with "-" charge, so when the temperature is above $0^{\circ} \mathrm{C}$, a part of water molecules on the frame may possess the energy for separating from the frame, and will move into the tunnel/vacancy, being as a "free water molecule". The total volume of the liquid water would decrease until to $4^{\circ} \mathrm{C}$ to the minimum. The ratio of density of solid water ice and liquid water is $11 / 12=0.916667$. (5) The relationships of the specific characteristics of the water with its construction, such as density, expansibility, compressibility, specific heat capacity, electric and thermal conductivity, solubility for $\mathrm{O}_{2}, \mathrm{H}_{2} \mathrm{~S}$, $\mathrm{NaCl}, \mathrm{KCl}$, etc. were discussed and numerical modeled. The experiments of saturated solution of $\mathrm{NaCl}$ audio-visual indicated that there are tunnel/vacancy spaces for storing $\mathrm{NaCl}$ molecules/ions, and increasing the volume of $1 / 11$ of water volume after freezing. (6) The surface structure of liquid water and the applications of research results are presented in other papers.
\end{abstract}

Keywords: Model of Water Molecule Structure, Ice and liquid Water Structure, Snowflake Forms and Self-similarity, Water Structure and Its Properties, Porosity Ratio of Water, Water as Solvent, Salts Dissolving Process in Water

\section{Introduction}

Water is the extremely important carrier for matter and energy circle in Earth Ecosystem including oceanatmospheric system. A lot of specific characteristics of water had been described, but it is still far from clearly understanding about the reasons of their formation. "What is the structure of water?" is the $46^{\text {th }}$ one of the essential frontier 125 scientific issues [1]. There was a model on structure of water [2], which described as the atom $\mathrm{O}$ in the center of a 
cubic box, and the $2 \mathrm{H}$ atoms stay at the two across corners. The other two across corners are occupied by electron clouds (Figure 1). The intersection angle between $\mathrm{H}-\mathrm{O}-\mathrm{H}$ is $109.5^{\circ}$, which is much bigger than the measured $104.5^{\circ}$ [3]. There is not a clear model for structure of water till now. A static balanced stable state model of water molecule is presented in this paper. The stable state is based on the dominant trajectories formed by random rotation electrons rounding three centers of $\mathrm{H}, \mathrm{O}, \mathrm{H}$ nucleus. The very specific stable structure of solid state of ice and snow and liquid state of water with huge flexibility are constructed on the basis of stable water molecules. "Haw the distinctive characteristics of water are related with its unique structure" would be analyzed and numerical simulated in this paper.

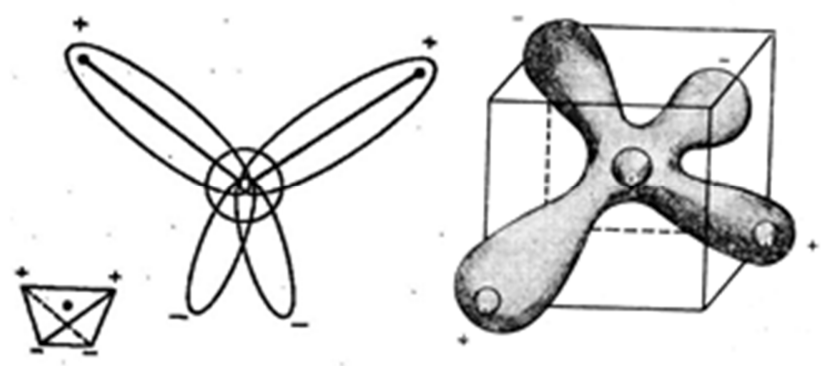

Figure 1. Certain sketch for water molecule [3].

\section{Structure Model of Water Molecule}

\subsection{An Equilateral Triangle Pyramid Model-ETP Model of Water Molecule}

There are 1 Oxygen atom and 2 Hydrogen atoms in water molecule. The hydrogen nucleus has positive electric charge. The electron has negative electric charge of $1 e=-1.602177$ $33 \times 10^{-19} \mathrm{C}$ (the proton in Hydrogen atom has electricity of positive "+" of $-e$ ). The mass of an electron is about 9.109389 $7 \times 10^{-31} \mathrm{~kg}$ [3]. The mass ratio of the hydrogen nucleus vs of electron is 1 833: 1 . The main mass of hydrogen is concentrated in its nucleus with a radius $10^{-5}$ of its atomic radius. The radius of an electron is $2.81794092 \times 10^{-15} \mathrm{~m}$. Thus, electron rotates round the $\mathrm{H}$ atom nucleus with radius of $0.053 \mathrm{~nm}$ [2] and speed of $2200 \mathrm{~km} \cdot \mathrm{s}^{-1}$ along the radon circle trajectories, and with high speed revolving on its own axis $(6.6$ $10^{15}$ circles/s). In a water molecule there are 2 hydrogen atoms, each of them has 1 proton with electricity of $-e$, and 1 "free electron", and can accept other additional electron rotating round their common nucleus with the same radius of random orbit and equal possibility of speed and directions. The oxygen atom can accept additional 1-2 electrons on its outer orbit sphere according to Bohr model. The most possible state is there are 2 "free electrons" may independently, (but under co-influence) rapid transit between $\mathrm{H} \leftrightarrow \mathrm{O} \leftrightarrow \mathrm{H}$ atoms and form some characteristic segments. Among the nucleuses of $\mathrm{H}-\mathrm{O}-\mathrm{H}$ there should be constructed a macro-stable static balance surround by electron rotation with trajectories of quasi-circle $\leftrightarrow$ hyperbola $\leftrightarrow$ ellipse and frequent changing transitions between them according to the laws of Columb's force and Kepler's movement rule. In view of scales of $10^{-15} \mathrm{~m}$ and $10^{-15} \mathrm{~s}$ all the oxygen and 2 hydrogen atoms would appear all "+", “-", " $0=$ neutral" states in certain direction or moment in water molecule. The "neutral state" for atoms of oxygen and hydrogen/s may assume only under view of larger scale and statistic meaning. For easier understanding we assume the core of $\mathrm{H}-\mathrm{O}-\mathrm{H}$ is in the kernel of the water molecule frame $\left(\mathrm{H}^{+}-\mathrm{O}-\mathrm{H}^{+}\right.$in Figure 2), and its pattern is similar the outer pattern (self-similarity). Suppose the distances between $\mathrm{H}^{+}-\mathrm{H}^{+}$ and $\mathrm{H}^{+}-\mathrm{O}$ are $b=\mathrm{H}^{+}-\mathrm{H}^{+}=\left(\mathrm{A}^{+}-\mathrm{B}^{+}\right) / \eta$ and $b_{2}=\left(\mathrm{O}-\mathrm{H}^{+}\right)=\left(\mathrm{O}-\mathrm{A}^{+}\right) / \eta$ separately. Here $\eta$ is the coefficient of geometrical similarity. There are repulsive forces among their nucleuses, which should be balanced by attraction forces among the concentrated negative electron cloud and nucleuses. Exist two "-" clouds in distances of $b \eta=\tilde{C} \bar{D}$, and two "+" points of distances of $b \eta=\mathrm{A}^{+}-\mathrm{B}^{+}$may construct a frame pyramid with 6 equal edges and $60^{\circ}$ angle between the connecting lines. The corn $\mathrm{H}^{+}-\mathrm{O}-\mathrm{H}^{+}$is in the kernel of the frame and the electron trajectories occupy by the pyramid (Figure 2c), which has the same pattern as the outer pattern of the water molecule (according with the principle of self-similarity in nature).

Take Figure 2 as the core of water molecule. 1) Assume each electron of $\mathrm{H}$ has flied out from $\mathrm{A}^{+} / \mathrm{B}^{+}$and "freezed" at $\mathrm{C}^{-} / \mathrm{D}^{-}$. The attractive Coulomb force $f_{1}$ between $A D, A C(B D$, $B C$ ) in direction of $A B(B A)$ are $-2 \kappa e^{2} b^{2} \cos 60^{\circ}$ (where. $\kappa$ is Coulomb's constant), which is equal (absolute volume) the repulsive force between $A B: f_{2}=-\kappa e \quad b^{-2}=-f_{1}$ at this moment. 2) When each $\mathrm{H}$ atom has an electron and appear "neutral", along $A B$ there is no repulsive force. 3) When there are $1 / 2$ possibility of electron at certain time interval at $\mathrm{C}^{-} / \mathrm{D}^{-}$, and at $\mathrm{A}^{+} / \mathrm{B}^{+}$, the attractive force between $A D, A C(B D, B C)$ in direction of $A B(B A)$ are $-\kappa e^{-} b^{2} \cos 60^{\circ}$ and is equal the repulsive force along $A B$. Therefore this kind of structure of $\mathrm{H}^{+}-\mathrm{O}-\mathrm{H}^{+}$core may keep a dynamic stable one in averaged statistic meaning.

We may discuss the possible situations: 1) One or two electrons may stable rotate round each $\mathrm{H}_{1}, \mathrm{H}_{2}$ atom or $\mathrm{O}$ atom. These 3 positions may assume as 3 characteristic segments (we mark them as, I, II, III) (electrons may stay there for a "long time" in comparison with the scales of $10^{-15} \mathrm{~m}$ and $10^{-15}$ s"). 2) The rolling electron round atom $\mathrm{H}_{1}$ (equally $\mathrm{H}_{2}$ ) may be attracted by atom $\mathrm{O}$ and rush to atom $\mathrm{O}$ and "captured" by atom $\mathrm{O}$ and rotate round it, 3) or if the speed of electron toward atom $\mathrm{O}$ is high enough, the electron will glance aside atom $\mathrm{O}$ along hyperbolic curve and leave away from atom $\mathrm{O}$, until the apogee -1 . Here electron has minimum of changing position in space. We may mark the electron cloud concentrated position as $\mathrm{IV}^{\text {th }}$ segment; (equally there is -2 on the other symmetrical corner as $\mathrm{V}^{\text {th }}$ segment. Because the $\mathrm{H}_{1}$, $\mathrm{H}_{2}$ are distributed symmetrically on the 2 sides of atom $\mathrm{O}$, and the rotation trajectories of electrons may have "left rotation" and "right rotation", so -1, -2 locate symmetrically). The electron will return toward to atom $\mathrm{O}$ along ellipse trajectory. The round-trip between the atom $\mathrm{O}$ and the apogee $\mathrm{O} \leftrightarrow-1$ (equally -2) may assume the other possible "long term stop position" as VI, VII). The analog discussions may be on the electrons moving from atom $\mathrm{O}$ to $\mathrm{H}_{1}, \mathrm{H}_{2}$. There will be 
cases at maximum apogee positions: $+1,+2$ with minimum of changing position in space, and the round-trip between the atom $\mathrm{O}$ and the apogee $\mathrm{O} \leftrightarrow+1$, (equally +2 ): VIII, IX, X, XI. The reasons for indication of $+1,+2$ at apogees on the $\mathrm{H}$ atoms sides are: when there is no any electron rotates round the atom $\mathrm{H}$ at this position should appear "+" electricity; there just should appear "_" when electron moves here instantly. Here we have much more possibility of "+" electricity then "_" electricity. Finally we may have total 11 characteristic "long term stop positions, as characteristic segments" for moving electrons in a water molecule.
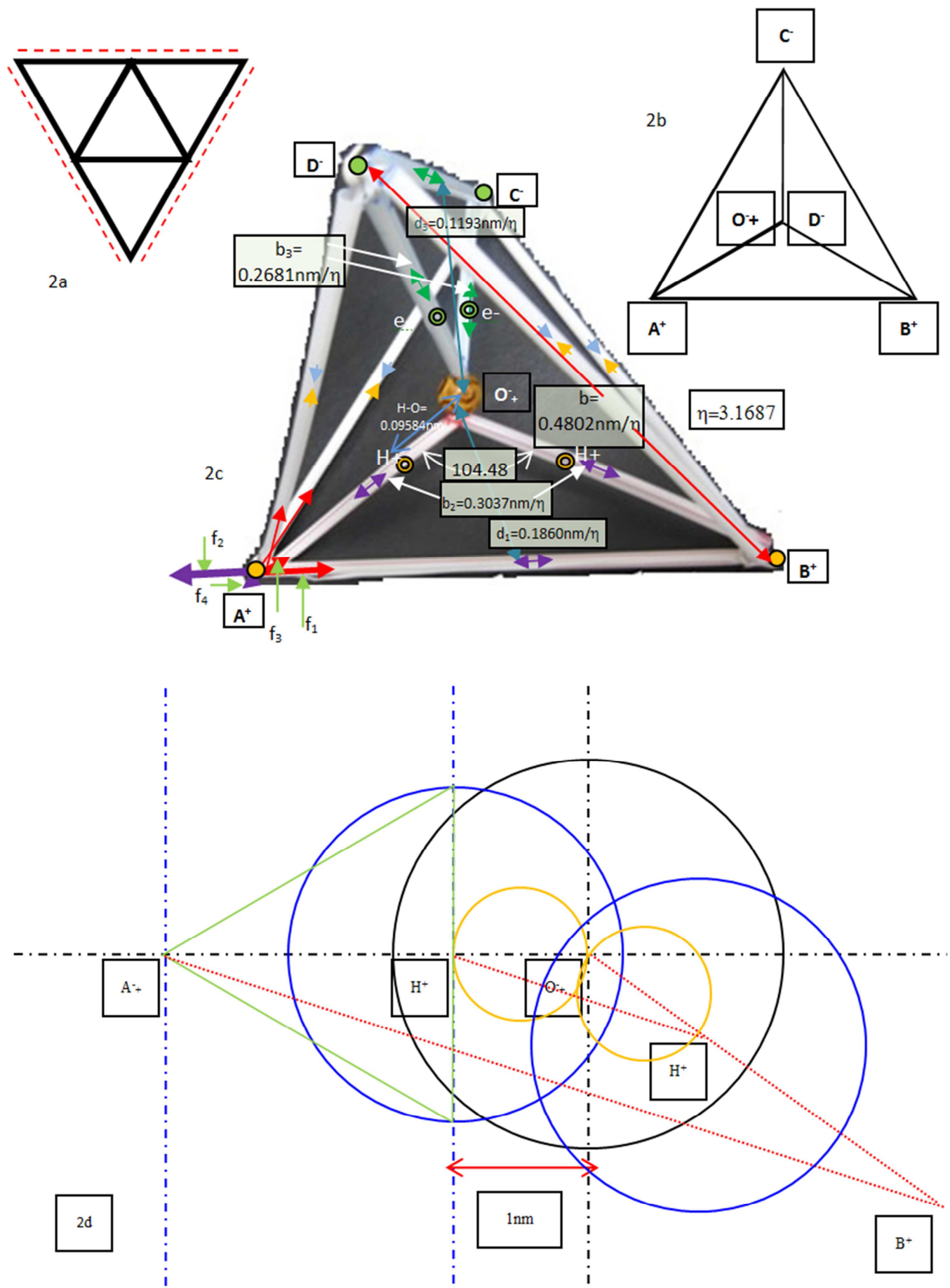

Figure 2. Sketch of water molecule. The nucleus of $H^{+}-O_{+}^{-}-H^{+}$as the core of water molecule are located in the kernel. The electrons move as screw type circulation with high speeds round them. The endpoints of A, B (appear "+" charge) and C, D (appear "-" charge) are the apogees (maximum distances and turn points) of ellipsoid tracks of electrons. The water molecule and its core are self-similarity with geometric similarity coefficient of $\eta$. The marked distances are the sizes of the core, and the molecule's sizes are the same when $\eta=1$. The figure of ABCD is an equilateral triangle pyramid (ETP Model of water molecule) with 6 equal edges. (Ref. Table 2).

Because the electros may have 11 characteristic segments with relatively "stable state", the most possible distribution of 
possibility is equal probability $1 / 11$ for each "segment". Because there are 2 "free electrons" from 2 atoms $\mathrm{H}$, so there are $1 / 11$ possibility, when 2 electrons meet at the electron cloud vertexes $\mathrm{C}^{-}$and/ or $\mathrm{D}^{-}$. The 2 electrons meet at $\mathrm{C}^{-}$or $\mathrm{D}^{-}$ instantly (here has double electricity) have very important meaning, when we will discuss the different structure of solid (ice) and liquid water.

\subsection{Calculation for Main Parameters of Water Molecule}

For calculation of the angle $\mathrm{H}-\mathrm{O}-\mathrm{H}$, we assume the length of a side of the equilateral triangle is $b$ (the edge of the pyramid with 4 equilateral triangles), the height of the equilateral triangle plane is $h$, the height of the pyramid is $h_{0}$, the included angle is $\varphi=30^{\circ}$, the included angle of $\mathrm{H}-\mathrm{O}-\mathrm{H}$ is $\varphi_{l}$ (Figure 3). The atom oxygen is located at $\mathrm{O}$, which is in distance of $\lambda h_{0}$ above the center of equilateral $\Delta \mathrm{A}^{+} \mathrm{D}^{-} \mathrm{B}^{+}$. The 2 hydrogen atoms are located at $\mathrm{A}^{+}$and $\mathrm{B}^{+}$, separately. For simplifying the explanation, we take $b$ as the characteristic length. In this case, the dimensionless $b^{*}=b / b=1$. We may neglect the dimensional symbol “*”. Therefore, we have parameters $b=1$, and $b_{2}, h, h_{0}$. From Figure 3 we have $\varphi=30^{\circ}$, $h=\cos \varphi, h_{0}=(8 / 9)^{1 / 2} \cos \varphi, b_{l}=(2 / 3) \cos \varphi, b_{2}^{2}=\left[\lambda h_{0}\right]^{2}+[(2 / 3) h]^{2}$.

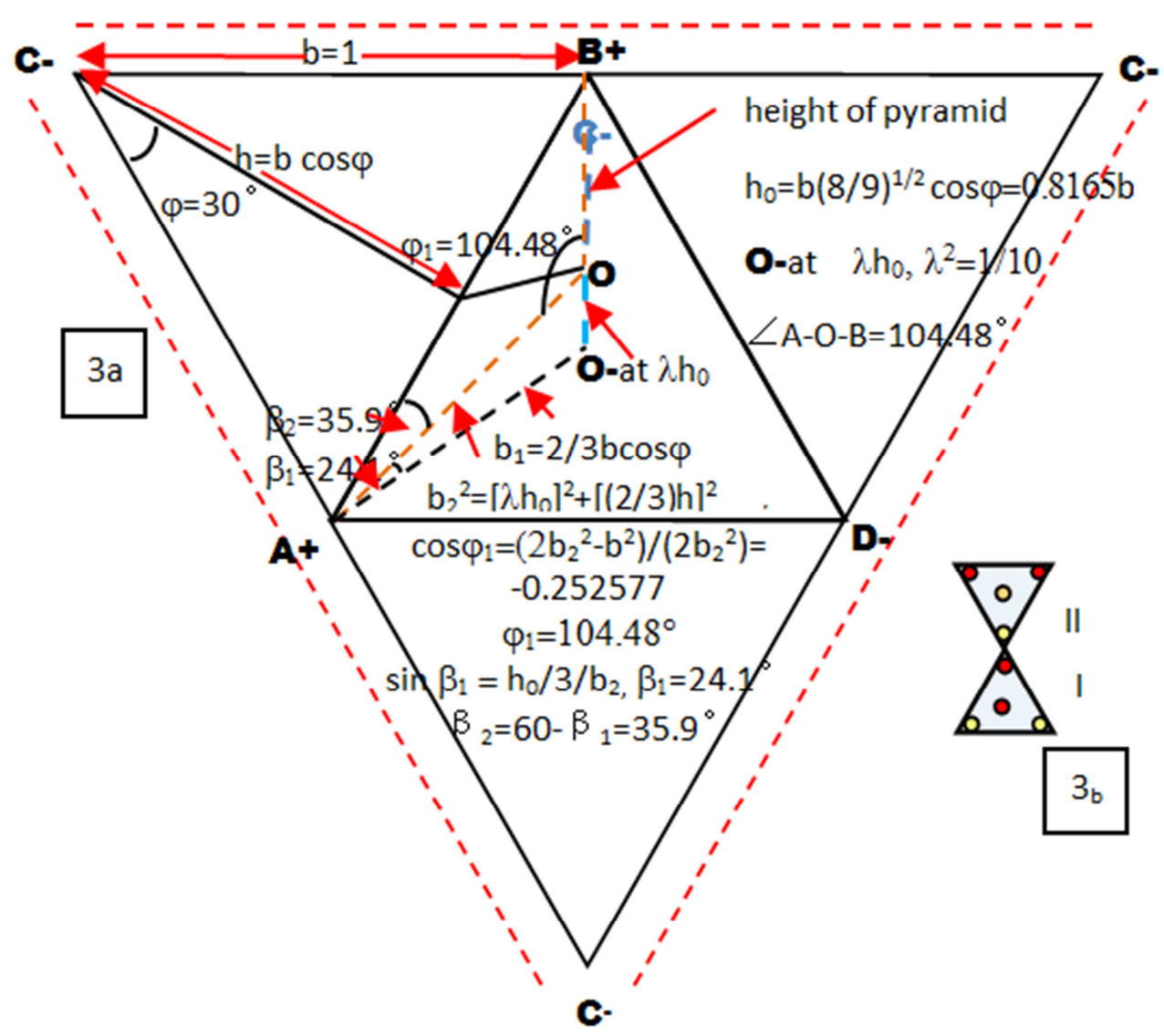

Figure 3. Sketch of calculation for molecule construction. The pyramid with 4-equilateral triangles and 6-equilateral edges of b (Length in calculation was divided by edge $b$, using nondimensional parameter); height of equilateral triangles is $h=b$ cos $\varphi$. while $\varphi=30 ;$ height of pyramid $h_{0}=b(8 / 9)^{1 / 2}$ cos $\varphi \tilde{=} 0.8165 b$; $O$-atom is located at $\lambda h_{0}, \lambda^{2}=1 / 10 . \angle A-O-B=104.48^{\circ}, \angle C^{-}-O-D^{-}=133.43^{\circ} ;\left(O-C^{-}\right)=0.91\left(O-A^{+}\right)$; The water molecule can be symbolized as I, II in Figure $3_{b}$; red circles—as “+” and yellow-as “-” charges, respectively; center circle—red "+" charge upward and yellow-"-" charge downward.

Set up $\angle \mathrm{A}^{+} \mathrm{OB}^{+}=\varphi_{1}$ in isosceles triangle $\triangle \mathrm{A}^{+} \mathrm{OB}^{+}$. According to the measured data, $\varphi_{I}=104.5^{\circ}[3]$, or $104.45^{\circ}$.

We may have [4]: $\cos \varphi_{1}=\frac{2 b_{2}^{2}-b^{2}}{2 b_{2}^{2}}=1-\frac{1}{2} \frac{b^{2}}{b_{2}^{2}}$

From where, when $\lambda^{2}=1 / 10(\lambda=0.31623<1 / 3$, take attention that $1 / 3 h_{0}$ is the crossover point of the perpendiculars of the triangle), $\left(b_{2} / b\right)^{2}=2 / 5,\left(b_{2} / b\right)=0.632456 ; \varphi_{I}=104.4775^{\circ}$. This specific angle is one of the specific angles such as $60^{\circ}, 90^{\circ}$, $120^{\circ}, 180^{\circ}$, when the ratio of the square of the hypotenuse to the square of the isosceles side is the rational number (Table $1)$.

1 https://en.wikipedia.org/wiki/Properties_of_water;
Table 1. Relationship between $\varphi_{1}$ and $\left(b / b_{2}\right)^{2}$.

\begin{tabular}{llllll}
\hline$\left(\mathbf{b} / \mathbf{b}_{2}\right)^{\mathbf{2}}$ & $\mathbf{1}$ & $\mathbf{2}$ & $\mathbf{2 . 5}$ & $\mathbf{3}$ & $\mathbf{4}$ \\
\hline$\varphi_{1},{ }^{\circ}$ & 60 & 90 & 104.48 & 120 & 180 \\
\hline
\end{tabular}

The distance between atom of Oxygen and atom of Hydrogen $o h=0.09584 \mathrm{~nm}$ and the van der Waals radii of the Oxygen and Hydrogen atoms are $r_{H}=0.12 \mathrm{~nm}$ and $r_{O}=0.14 \mathrm{~nm}$ as measured (Table 2) $[3,4,5]$. So $\mathrm{OH}^{+}<r_{H}+r_{O}$. It means that the distance between the Oxygen atom and the Hydrogen atom is less than the sum of their van der Waals radiuses, namely, both van der Waals radiuses are overlapping [5, 6], the electrons on Oxygen/ Hydrogen atoms may transit from one to 
another. The maximum length when an electron might fly from the outer orbit of Oxygen atom pass throw outer orbit of Hydrogen along the externally- tangent with an angle of incidence of $30^{\circ}$ and an angle of refraction of $30^{\circ}$ is $b_{2 \max }=\mathrm{OH}^{+}+r_{H} / \tan 30^{\circ}=0.303686 \mathrm{~nm}$. The edge length of the principle pyramid of water molecule is $b=b_{2 \max } \times(5 / 2)^{(1 / 2)}$ $=0.48017 \mathrm{~nm}$. Because the coefficient of geometrical similarity is $\eta=b_{2} / o h=0.303686 / 0.09584=3.1687$, so the length of the core edge $b_{c}=b / \eta=0.151536 \mathrm{~nm}$. Therefore the volume of the water molecule pyramid $v=0.013047 \mathrm{~nm}^{3}$ is the 31.8 multiple of the self-similarity core.

All the discussions on Figures 2 and 3 are for the core region of the water molecule, which is located in the position of $\mathrm{H}^{+}, \mathrm{O}^{-}, \mathrm{H}^{+}$in Figure 2c. The 2 electrons of the 2 Hydrogen atoms move quasi- screw type among the 3 nucleuses of Hydrogen $\leftrightarrow$ Oxygen $\leftrightarrow$ Hydrogen in the frame of 4 equilateral triangles pyramid of water molecule. The most far away positions from the core are the 4 peaks of the pyramid: $A^{+}, B^{+}, C^{-}, D^{-}$. The distance from the Hydrogen atom to the "+" peak is $0.20785 \mathrm{~nm}$. The distance between the peaks "+" and "-" is $0.48017 \mathrm{~nm}$ (the length of the edge of the pyramid). It means there are obvious effective forces between electricity of "+" and "-." in such distance. The length from the Hydrogen to the " + " peak of the pyramid is $0.48-0.21 \approx 0.27 \mathrm{~nm}$ (about $56 \%$ of the edge of the pyramid). If the distance between the peaks of two water molecule less than $0.27 \mathrm{~nm}$ the two molecules might attract/ repel each other under the effect of Coulomb force.

\subsection{Stereoscopic Electric Dipole Moment of Water Molecule}

According to the above discussion, there are pyramids both for water molecule and its internal corn with 4 equilateral triangles and 4 peaks at the ends of one edge with "+" "+" electricity (the line $A^{+} B^{+}$in Figure 2c, and Figure 3) and the other edge with "-", "."” electricity (the line $\mathrm{C}^{-} D^{-}$in Figure 2c and Figure 3). The vertical distances from the Oxygen atom to these edges are $d_{1}, d_{3}$, separately (Figure 2c), and we have: $\left(d_{1} / b\right)^{2}=\left(b_{2} / b\right)^{2}-(1 / 2)^{2} ;$ and $\left(d_{3} / b\right)^{2}=\left(b_{3} / b\right)^{2}-(1 / 2)^{2}$.

From where, we have $d_{1}=0.18597 \mathrm{~nm}, d_{3}=0.11927 \mathrm{~nm}$; $d_{1}>d_{3}, d_{1}-d_{3}=0.06670 \mathrm{~nm}, d_{1}+d_{3}=0.30524 \mathrm{~nm}$; Oxygen atom is more far away from the "+" edge than "-" edge. The Oxygen does not locate at the real centre of the pyramid, but with deviation to side of "-" edge caused by force of mutually repel with "+" edge of 2 Hydrogen atoms (see Figure 2).

The stereoscopic electric dipole moment of water molecule is $p=2 \gamma_{1} e b_{c}$, where the electricity of 1 electron $e=-1.602$ $177 \times 10^{-19} \mathrm{C} ; \gamma_{1} e$ is the real electricity. Obviously, $\gamma_{1}<1, b_{c}$ is the edge of the core of water molecule. Therefore, $p / \gamma_{1}=0.485$ $576 \times 10^{-19} \mathrm{C} \cdot \mathrm{nm}$. The measured value $p$ of water molecule is $0.069562 \times 10^{-19} \mathrm{C} \cdot \mathrm{nm} \quad[3,4,8]$. Thereafter, $\gamma_{l}=0.143$ $257 \approx 1.58 / 11$. This result is of believable one, because of the possibility of 2 electrons cloud at the one peak should be between $1 / 11 \sim 2 / 11$.

Table 2. Sizes of water molecule, pyramid with 4 equilateral triangles; Unit: length, nm; volume, $\mathrm{nm}^{3}$.

\begin{tabular}{llllllll}
\hline I & II & III & IV & V & VI & VII & VIII \\
\hline 0.09584 & 0.12 & 0.14 & 0.303686 & 0.48017 & 0.013047 & 0.151536 & 0.000410 \\
\hline
\end{tabular}

I.- Distance between H-O atoms; II.-van der Waal's radius of H atom; III.- van der Waal's radius of O; IV.-Distance between O atom and “+” endpoint; V.-Length of pyramid edge of water molecule; VI.-Volume of water molecule pyramid; VII.-Core edge length of water molecule pyramid; VIII.-Core volume in water molecule pyramid; IX-Ratio of water molecule volume to its core volume. (Ref. Figure 2d).

We may take a simplified model of static balance on the "frozen model" of the water core. The atoms H-O-H stay at $\mathrm{A}^{+}-\mathrm{O}-\mathrm{B}^{+}$. The electron of each Hydrogen atom has "flied out" and passing through at the "--" endpoint $\mathrm{C}^{-} / \mathrm{D}$ - It is mainly balanced by the centrifugal force and attractive force by Oxygen atom (and also by repulsive force between 2 electrons at $\mathrm{C}^{-} / \mathrm{D}^{-}$, and attractive forces between hydrogen nucleus and the electrons, under equilateral triangle construction). We assume the electron stay "froze" at point $\mathrm{C}^{-} / \mathrm{D}^{-}$; and 1 (each for 1 Hydrogen) electron (of the Oxygen atom) static face to $\mathrm{C}^{-} / \mathrm{D}^{-}, \gamma_{2}$ electrons (of the Oxygen atom) static face to $\mathrm{A}^{+} / \mathrm{B}^{+}$. At this moment the repulsive force between the 2 Hydrogen atoms $f_{2} \quad\left(f_{2}=\kappa \gamma_{1} e^{2} / b^{2}\right)$ is balanced by attractive forces between the 2 ".-" points at $\mathrm{C}^{-}, \mathrm{D}^{-}: \kappa \gamma_{1} e^{2} 2 \times \cos 30^{\circ} / b^{2}=f_{2}$ (see Figures 2, 3). Similarly, the repulsive force between the 2 electrons at $\mathrm{C}^{-} / \mathrm{D}^{-}$point is balanced by the attractive forces between the electron and the hydrogen nucleus. The repulsive force between the Hydrogen atom and Oxygen atom is balanced by attractive force between the Hydrogen nucleus and the electrons on Oxygen atom, facing to the Hydrogen nucleus: $f_{4}=f_{3}$ (Figures 2,3). The total interaction forces between the Oxygen and Hydrogen atoms content the repulsive force between the protons in Oxygen and Hydrogen atoms and attraction forces among their protons and electrons may be described as $f_{4}=\kappa \gamma_{2} e^{2} /\left(b_{2}\right)^{2}$, which should be balanced by the sum of the components of the total compress (push) force caused by attraction force between "+" and 2 "-” end points at point $\mathrm{A}^{+}$toward the Oxygen atom in distance of $b$ : $f_{3}=\kappa \gamma_{3} 2 \times e^{2} /\left(b \cos \beta_{2}\right)^{2}$ (see Figure 2c). From where, $f_{4}=f_{3}$, and $\gamma_{2} / \gamma_{3}=\left(b_{2} / \mathrm{b}\right)^{2} \cos ^{2} \beta_{2}=1.72720 \approx 1.73$. It seems the 8 electrons in atom oxygen distribute as: $1 e$ face to $\mathrm{C}^{-}, 1 e$ face to $\mathrm{D}^{-}, 1.73$ $e$ face to $\mathrm{A}^{+}, 1.73 e$ face to $\mathrm{B}^{+}$, other $2 \times 1.27=2.54 e$ face to other directions. This seems that the model simplifies as following static picture: there are 2 "-" electrons "sitting" on the 2 negative endpoints (each for 1), no electron with Hydrogen atom and the Oxygen atom appears has negative of 1.73 "." electron in the face toward to Hydrogen atom (electrons on Oxygen atom more densely distributed/ more frequently "visited" the direction of Hydrogen atom. The dynamic stationary balance among the atoms of the isosceles triangle of $\mathrm{H}-\mathrm{O}-\mathrm{H}$ may be realized by the repulsive and attraction forces among the "+" protons and the "-" electron clouds at the frame, when the opposite vertical angle of the isosceles triangle $\varphi_{I}=104.4775^{\circ}$ (Figure 3), namely the square of the ratio of the opposite side to the isosceles side is 5/2: $\left(b / b_{2}\right)^{2}=5 / 2$ (see Table 1$)$. Of course, this is just a very 
simplified model for understanding a picture possible at one moment. Real processes in microscopic scale of time and space are related with very complex issue of quantum mechanics. We may take this model as a stationary model for study on the mezzo-macro process and ignore the micro stochastic aspects of the real processes.

\subsection{The Basic Characteristics of Water Molecule}

The 4 peaks may be mark as $\mathrm{A}^{+}, \mathrm{B}^{+}, \mathrm{C}^{-}, \mathrm{D}^{-}$for easy discussion (Figure 2). They are the extreme far positions (apogees), where the electrons can reach to with some possibilities and relative "slow visiting speed" during their high speed movement round the H-O-H system. The 2 Hydrogen atoms do not stay at $\mathrm{A}^{+}$or $\mathrm{B}^{+}$, but at $\mathrm{H}^{+}\left(\mathrm{H}_{1}\right), \mathrm{H}^{+}\left(\mathrm{H}_{2}\right)$ (Figure 2). For example, when the electron returns to peak $\mathrm{A}^{+}$with certain possibility, here will appear "-" negative electricity. If there are no electron at $\mathrm{A}^{+}, \mathrm{H}^{+}\left(\mathrm{H}_{1}\right)$, and segment $\left[\mathrm{A}^{+}-\mathrm{H}^{+}\left(\mathrm{H}_{1}\right)\right]$, the possibility would be $2 \times(3 / 11)=6 / 11$ (each electron on 2 Hydrogen atom does not reach to the outside of segment $\mathrm{O}-\mathrm{H}_{1}$ ). Therefore, the possibility of "+" electricity at $\mathrm{A}^{+}$would be about $(11-2 \times 3) / 11=+5 / 11$. There are 3 segments at $\left[\mathrm{C}^{-}\left(\mathrm{E}_{\mathrm{a}}\right)\right]$, $\left[\mathrm{C}^{-}\left(\mathrm{E}_{\mathrm{a}}\right)-\mathrm{O}\right]$, and $\mathrm{O}$ on the direction of $\mathrm{C}^{-}-\mathrm{O}$. Therefore, the possibility for appear "-" electricity at $\mathrm{C}^{-}$would be $(2 \times 3) / 11=$ “-”6/11 (each electron [with possibility of 1/11] of 2 Hydrogen atoms may appear at these 3 segments). The same situation is for $\mathrm{D}^{-}$. In summary, at the 2 peaks, where there no Hydrogen atom, would appear "--" $6 / 11$ possibility, and at the 2 peaks with Hydrogen atom would appear "+" 5/11 possibility. Thereafter, the water molecule possesses electric moment. It was measured as $0.069562 \times 10^{-19} \mathrm{C} \cdot \mathrm{nm}[3,4,7]$. The calculated value according to above model is $\gamma_{1} \times 0.485576 \times 10^{-19} \mathrm{C} \cdot \mathrm{nm}$. So $\gamma_{I}=0.142257 \approx 1.58 / 11(\operatorname{see} \$ 2.3)$.

In this way, the stereoscopic pyramid model of water molecule with 4 equilateral triangle surfaces may be indicated as a plan equilateral triangle (see Figure $3 b$ ) with 2 red circles (means "+"electricity) and 2 yellow circles (means "-"electricity) at the peaks of the equilateral triangle, and the red /or yellow circles in the center of the equilateral triangle indicates that the pyramid peak is upward/ or downward with "+" /or "-" electricity. In this coupling model, the any plane of the pyramid of the water molecules I (or II) parallels the corresponding plane of the molecule II (or I). The coupling molecules I and II have parallel planes but opposite directions of their pyramid endpoints with opposite electricity under averaged dynamic balance.

\section{Structure Models for Liquid Water and Ice, Snow as Solid Water}

\subsection{Structure Model for Water Ice}

Because the water molecule does not a sphere, but a pyramid with 4 equilateral triangle planes and 4 peaks of 2 pair of " $+/-$ " electricity possessing obvious stereo electric dipole moment, therefore the structure of solid water ice should related with coupling of "+" "." endpoints with symmetry and equality of possibility of "upward" or "downward" relative to certain plan, and each plan of each water molecule will parallel each others. Assume there is a water molecule, which is sitting on the horizontal plane with upward endpoint of "+". It had 3 endpoints with electricity of "_-", “+”"“-”in the same horizontal plane. This molecule may be named as a "core molecule", no loss generality as shown in Figure 3b I. The "+"/or "-"” endpoint of the core molecule may be electric coupled with "_" /"+" endpoint of another water molecule with downward "+" endpoints (total 4 downward water molecules as shown in Figure $3 \mathrm{~b}$ II). 3 of them around the core water molecule in a common plan and the $4^{\text {th }}$ one downward (opposite direction of the core molecule) molecule is coupled at the vertical peak core molecule. Each equilateral triangle planes of the water molecule pyramids may parallel the equilateral triangle planes of other water molecule pyramids. This arrangement of the adjacent water molecules with opposite (upward- downward) direction in a common plane may lead to more stable combination (each molecule has the equal possibility to possess-most possible of distribution, Figure 4a). The thickness of such "slice of water molecule structure" is 2 ( 1 upward and 1 downward) heights of molecule pyramid $(\approx 0.8 \mathrm{~nm})$. There are obvious hexagon spaces with length of a side of the edge of water molecule $(\approx 0.5$ $\mathrm{nm})$. Analogously, we may construct the other slice of water molecule structure and couple these two slices in one thicker slice, according to the principle of "+" "-" endpoints coupling, as a stereoscopic structure (rise vertically in $2 h_{0}$ and move along one of the edge of pyramid horizontally in $1 b$, Figure $4 \mathrm{~b}$ ). Such structure can be expended to the whole three dimensional space of water ice with the empty serial tunnels of hexagon section, where there no electricity and has very low conductivity, but can store different gaseous, liquid, solid matters in the empty space, and form Zigzag Hexagon Tunnel-vacancy System as the specific structure of solid water ice (ZHTVS model-constructed by ETP model of water molecule). The scales are: the length of edge of water molecule $b=0.48017 \mathrm{~nm}$, area of equilateral triangle $\mathrm{s}=0.19967 \mathrm{~nm}^{2}$, the distance between two parallel edges and the length between the two points of the opposite angle of the hexagonal sections of the ice cages are 0.83168 , and $0.96034 \mathrm{~nm}$, separately; and the area of the sections are $0.69169 \sim 1.19804 \mathrm{~nm}^{2}$. Each empty hexagon plane (origin plane) has 6 isometric edges (may be named as 1, 2, 3, 4, 5, 6, successively, Figure 4a), 3 of them (1, $3,5)$ are upward adjoin with similar hexagon plains in angle of $60^{\circ}$ to the origin plane, and 2, 4, 6 planes are downward adjoin with similar hexagon planes in angle of $60^{\circ}$ to the origin plane.

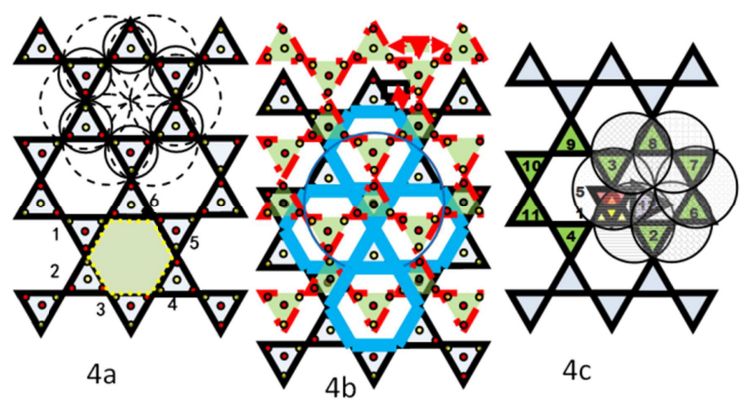

Figure 4. Sketch of water ice structure. 
4a: All one of the planes (three ends of the pyramids) of the water molecules pyramids are in one plane, but their forth ends are upwards (red color in center of the triangles)/ downwards (yellow color circles in center of the triangles) one by one alternately, each molecule has the parallel planes of pyramid. This one slice structure of water molecule has thickness of $2 h_{0}=0.78412 \mathrm{~nm}$.

$4 \mathrm{~b}$ : The other plane construction of water molecules, which is parallel and similar to $4 \mathrm{a}$ may be formed and strongly coupled with the $4 \mathrm{a}$ slice in a shift dislocation of molecules (rise vertically in $2 h_{0}$ and move along one of the edge of pyramid horizontally in $1 \mathrm{~b}$, Figure $4 \mathrm{~b}$ ). Therefore, the center of the hexagon empty space in one plane is in the face of a suspended molecule of the adjacent plane. This process may extend in the vertical directions endless and the solid state of water-- ice with giant number of "ice cages", characterized with hexagon profiles. The difference in coupling probability in vertical and plane as $(1 / 3)^{\mathrm{n}}$ leads to difference in growing speed of plane size and thickness of the crystals after a couple of growing processes ( $n$ times) of condensation, especially the water vapor in air will decrease rapidly after snow growing. Therefore, the snow crystals are much easier formed in temperature below zero in the atmosphere.

$4 \mathrm{c}$ : Surround a molecule with double "." electrons (yellow color) there are coupled 11 molecules $(1,2,3,4,6,7,8,9$, 10, $11^{\text {th }}$ in one plane, and the $5^{\text {th }}$ in vertical coupling as a frame) in close adjacency. The $12^{\text {th }}$ molecule is located interior in the "water cage", as a free molecule, and it can freely exchange its location with the "frame molecule". Therefore, the density of the liquid water is more than the ice. The existing of "free molecules" with probability of $1 / 11$ is the necessary and sufficient conditions for formation of the liquid water state.
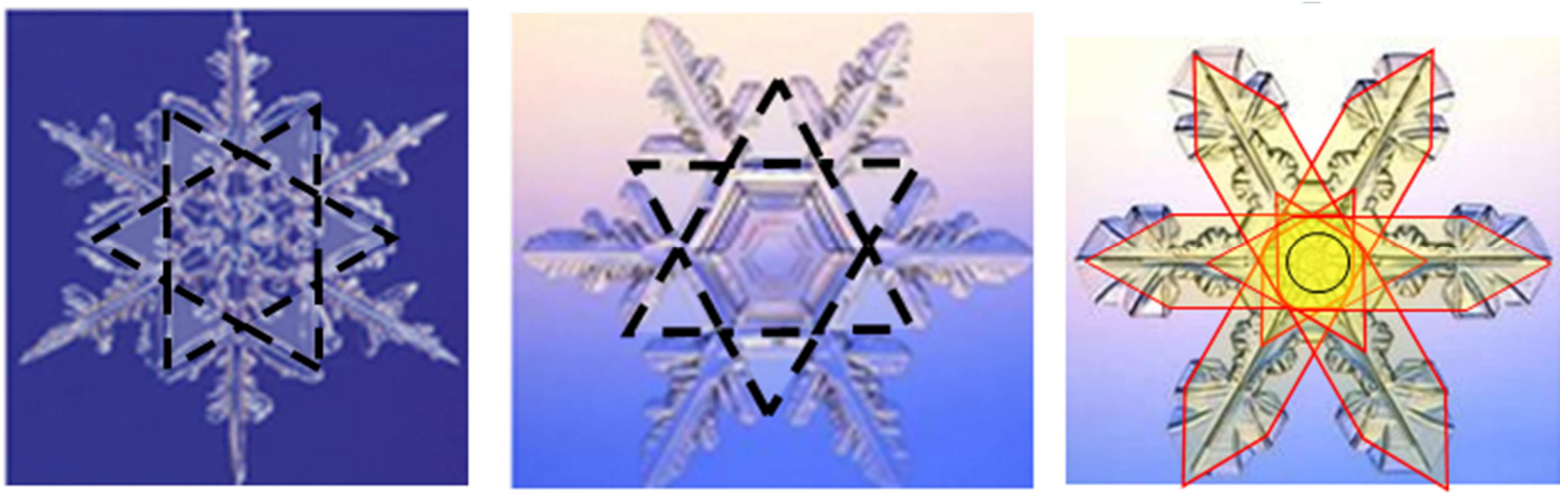

Figure 5. Samples of snowflakes with their self-similarity.

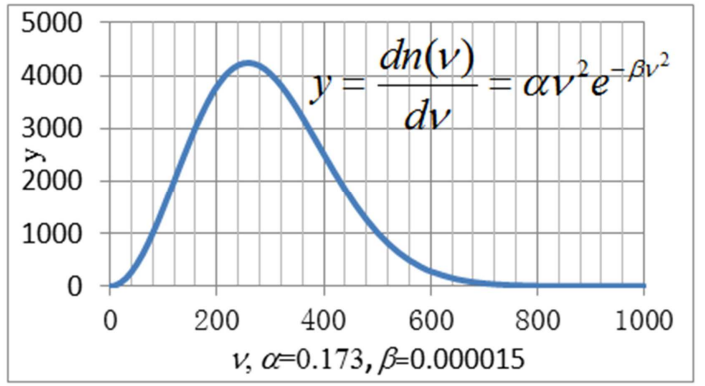

Figure 6. Sample of Maxwell distribution.

\subsection{Look at the Model of Water Ice from Point of View of Snowflake}

We will discuss on the consolidation of water molecules into solid state below $0^{\circ} \mathrm{C}$ (desublimation). Because around a core water molecule can couple 3 other water molecules in the same plane, but just 1 molecule in vertical direction, so the possibility for consolidation in the plane will $3^{\mathrm{n}}$ times more than in third (the vertical to the plane) dimension, especially in the condition of low air temperature and low concentration of water molecule. The possibility of formation for snowflake (slice model) will much more than that for ice (three dimension symmetry model) under air temperature below $0^{\circ} \mathrm{C}$. According to the principle of self-similarity the snowflakes have the basic forms of slice-hexagon (hexagon needle-like), which possess the basic characteristics of solid structure of water ice (Figure 5).

\subsection{Structure of Liquid Water}

A part of water molecule might have the kinetic energy above the threshold for separating itself from the water ice frame according to the Maxwell distribution (Figure 6) in relation with increase of temperature. In these cases the water molecules may increase the coupling distances and have possibility of leaving from the ice water frame. Usually they will still keep on the frame. Until at the moment when the adjacent to the endpoint of the other water molecule has "double electrons", this molecule may get into the empty cave of the frame (so decrease the volume of the ice framework) and water ice frame will newly reconstruct as a complete one in time scale about $10^{-15} \mathrm{~s}$. This kind of interchange process can lead to the soft (liquid) state of water. The liquid water can instantly adapt its configuration to whatever around hard boundary and can get into any micro chinks with length of nanometer, even into the mineral crystals as crystal water. The threshold temperature under one standard atmosphere pressure is $0^{\circ} \mathrm{C}$.

The possibility with double electron at one endpoint in water molecule is $1 / 11$ as analyzed in $\$ 1.1$. It means that there will be one molecule in the empty frame surrounded by 11 water molecules (Figure 4c). Thus, the volume of the liquid 
water will decrease and the density of liquid water will increase that of $1 / 11$ in comparison with ice. The density of ice is $11 / 12=0.9166667$ (density of water at $4^{\circ} \mathrm{C}$ under 1 standard atmospheric pressure is $1 \mathrm{~g} / \mathrm{cm}^{3}$ ), which is very close to the data of 0.9168 measured in 1973. The ice density was measured as 0.9164 in 1936 [7-9, f. n. 2]. The processes of leaving molecules from the water frame into the ZHTVS are realized from $0^{\circ} \mathrm{C}$ and stopped at $4{ }^{\circ} \mathrm{C}$, when the possibility of part molecules with kinetic energy more than the threshold one increase with temperature. The maximum possibility is $1 / 11$ for double electrons meet at one endpoint of water pyramid. So, after the temperature is higher than $4^{\circ} \mathrm{C}$, although all the molecules may have high kinetic energy and leave from the frame, but there only $1 / 11$ possibility to get into the ZHTVS of water structure. Really, the volume of the water molecule is very stable $\left(0.013047 \mathrm{~nm}^{3}\right)$ and the density of the liquid water will be determined by the coupling distance between molecules under different temperature and pressures in pure water and the dissolved materials in polluted waters.

The "free water molecule" leaving from the structure frame should locate not so far, but inner the distance of attraction by Coulomb force of the molecules at the water surface. Otherwise, this "free water molecule" may fly out from water surface and become a gaseous water molecule. According to the calculation, all the molecules in the liquid water of $100 \mathrm{~g}$ with density of $1 \mathrm{~g} \cdot \mathrm{cm}^{-3}$ will occupy the volume of 43.61538 $\mathrm{cm}^{3}$. If these molecules are compactly arranged in a box, the density will be $2.2928 \mathrm{~g} \cdot \mathrm{cm}^{-3}$. This compact state could not be realized for liquid water under high pressure in practice at present because of the existence of the ZHTVS structure of the liquid water. The gaseous state of water under high temperature and high pressure may possess high density much more than that of the standard density of liquid water of 1 $\mathrm{g} \cdot \mathrm{cm}^{-3}$. It was observed the density of gaseous water under temperature of $500^{\circ} \mathrm{C}$ and pressure of $250 \mathrm{kPa}$ at earth mantle in deep ocean as $2.16 \mathrm{~g} \cdot \mathrm{cm}^{-3}$ [10], which is less than that of above mentioned data. This fact is one of the evidences of the reasonability of the analysis in this paper. The molecule of heavy water $\left(\mathrm{D}_{2} \mathrm{O}\right.$, with molecular weight of 20.0275) has the relative molecular mass higher than that of the regular water $\left(\mathrm{H}_{2} \mathrm{O}\right.$ with molecular weight of 18.0153) and density of 1.056 $\mathrm{g} \cdot \mathrm{cm}^{-1}$ (about higher than that of regular water on $11 \%$ ). Its melting point is $3.82^{\circ} \mathrm{C}[7,11]$, which is more than $0^{\circ} \mathrm{C}$ (the melting point of regular water ice). It explains that for extricating the water molecule from the structure frame need more kinetic energy under higher temperature for $\mathrm{D}_{2} \mathrm{O}$ than that of for $\mathrm{H}_{2} \mathrm{O}$.

Solid and liquid state change associated with not only volume change but kinetic and potential energy exchange also. In fact, that the water molecules leave from the electric attracting point and associated with decrease of volume may led to asymmetric processes of leave from and joint into the water frame. The freezing of subcooled water may be needed certain additional conditions, except temperature, for example, crystal centers, energy transforming, etc. The mechanism of milting/ freezing process of water needs to be studied in detail.

\section{The Relationship of the Specific Characteristics of the Water with Its Construction}

\subsection{The Density, Expansibility and Compressibility of Water}

\subsubsection{The Density of Water}

There are "free water molecules" with possibility of $1 / 11$ in the frame cage. They may very frequently exchange their position with the molecules at frame in time scale of femtosecond $\left(10^{-15} \mathrm{~s}\right)$. Therefore the liquid water may adapt to the boundary of rigid bodies (include the outer and internal boundary of rigid bodies, floating, suspending and pelagic substances) and the changes of their states with the internal physical, chemical and biological parameters of the water itself. The macro characteristics of liquid water masses might be formed very quickly.

It is simple and convenient for modeling the distances between molecules in structure frame, if we suitably increase the length of the edge of the molecule. For example, the real length of the edge of the water pyramid is $d_{00}=0.4801699 \mathrm{~nm}$, we may take the expansion coefficient for edge length of the pyramid of water molecule is 0.001 (expansion rate of $0.1 \%$ ) at $0^{\circ} \mathrm{C}$. The invented length of the edge length of the pyramid will be $d_{0}=d_{00} \times(1.001) \mathrm{nm}=0.4806500 \mathrm{~nm}$; the coupling distance between the 2 molecules will be $2 \times\left(d_{0}-d_{00}\right)=0.960$ $3398 \mathrm{pm} \approx 1 \mathrm{pm}$.

The another parameter for describing the characters of the structure frame of the water is the ratio of total volume of the vacancy to the total volume of the molecules (which may be named as " $\varepsilon=$ porosity ratio of water"). According to the specific volume of the water under different temperature the parameters of coupling distances $d$ and the porosity ratio of water $(\varepsilon)$ may be calculated (Table 3 and Figure $7 \mathrm{a}$ ). The $\varepsilon$ is 2.28 when the water temperature is $\geq 4^{\circ} \mathrm{C}$. This porosity ratio can satisfy the rotation, vibration of the water molecule at the frame or move into the cave. The porosity ratios decrease from 2.286 to 2.28 under the temperature increase from 0 to $4^{\circ} \mathrm{C}$, because a part of the molecules gradually leave from the frame and get into the cave. The porosity ratios in subcooled water are about 2.3 2.326. It is of interest, that the density of the subcooled water at $-30^{\circ} \mathrm{C}$ is close to that at $+60^{\circ} \mathrm{C}$. It is not hard to see, that calculated data are very good accord with the measured data with the linearly dependent coefficient close to 1 (Figure 7b). The volume of water molecule determined by quantum mechanics and does not change with usual temperature variation, but the coupling distances $d$, the sphere of activity--“manor" of water molecule may increase with increase of temperature. So the porosity $\varepsilon$ and $d$ are two independent parameters.

Except subcooled water under temperature $0^{\circ} \mathrm{C}$, there are glass state of water, which density is similar to that of under temperature $>0{ }^{\circ} \mathrm{C}$, the supercritical fluid, which is extremely sticky. The transform between solid and liquid water is related with different transform and convert form of energy, such as the kinetic, potential, chemical, radiation, conduction, etc. The molecule with higher kinetic energy will has more possibility 
for leaving from the frame, absorbing kinetic energy into potential energy as "latent heat". The water frame is constructed by attraction force between molecules, and the melting process from solid state of ice to liquid water, which is associated with decrease of the volume will take place easier than that of the process from liquid water to ice.

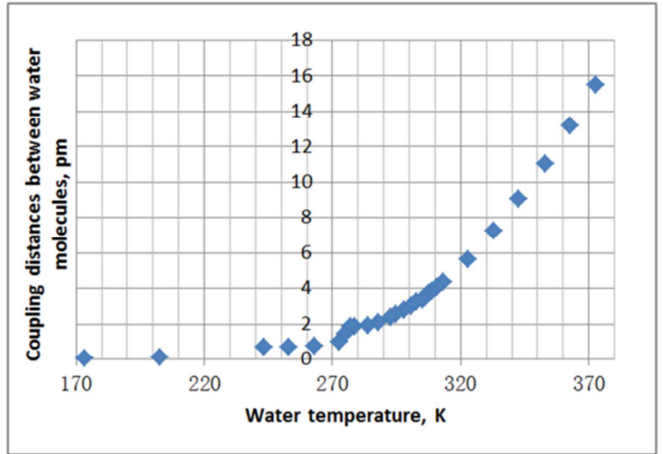

a
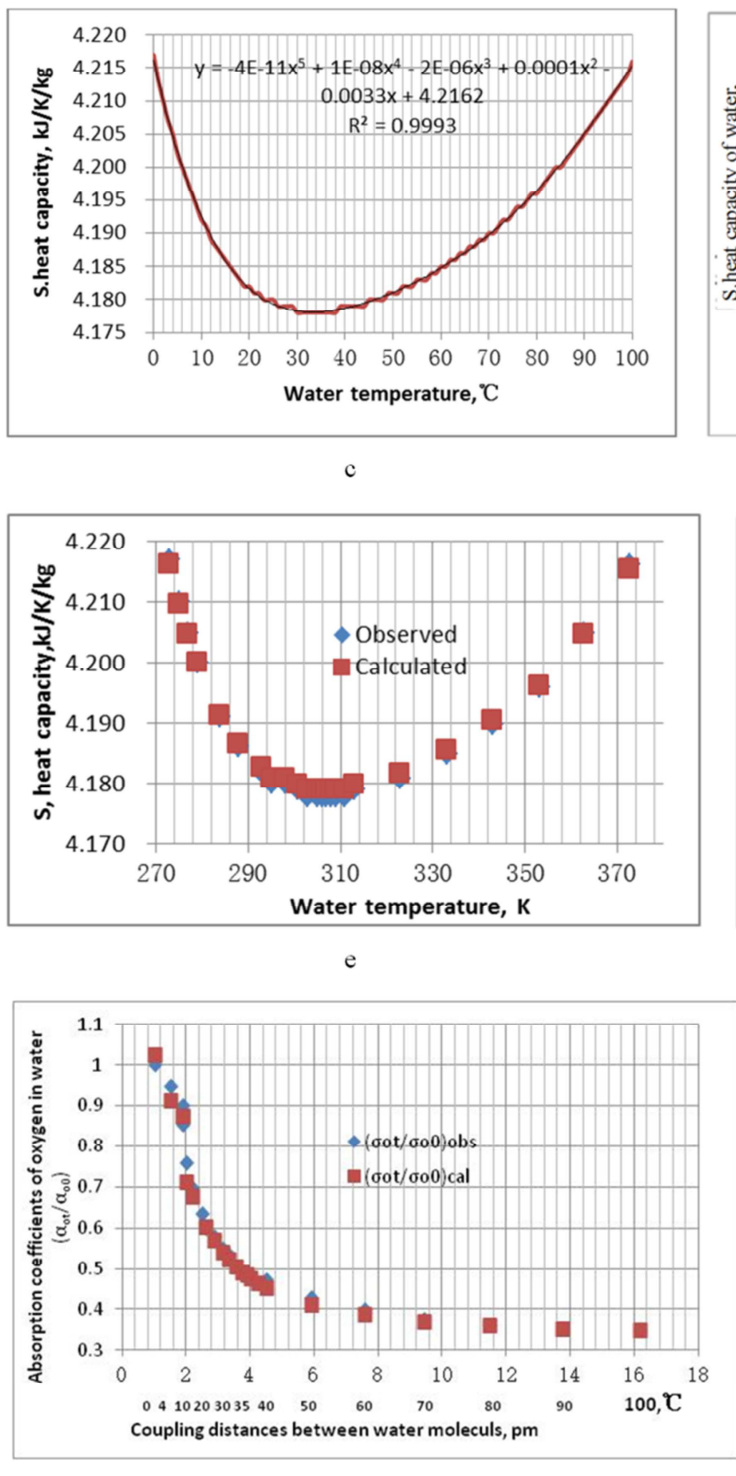

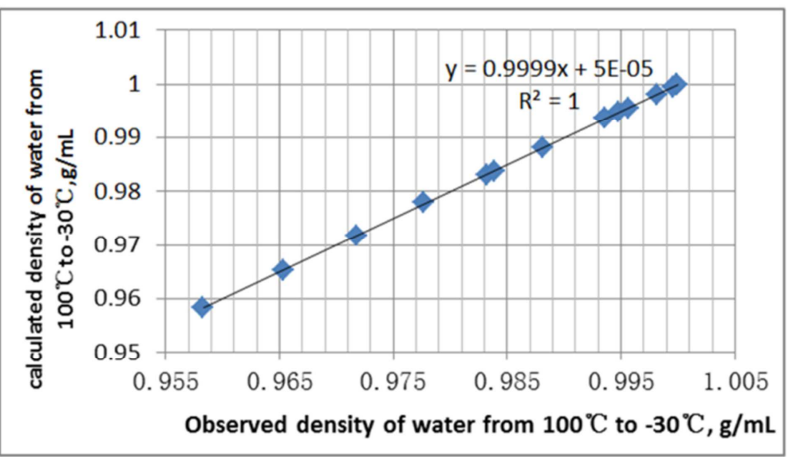

b

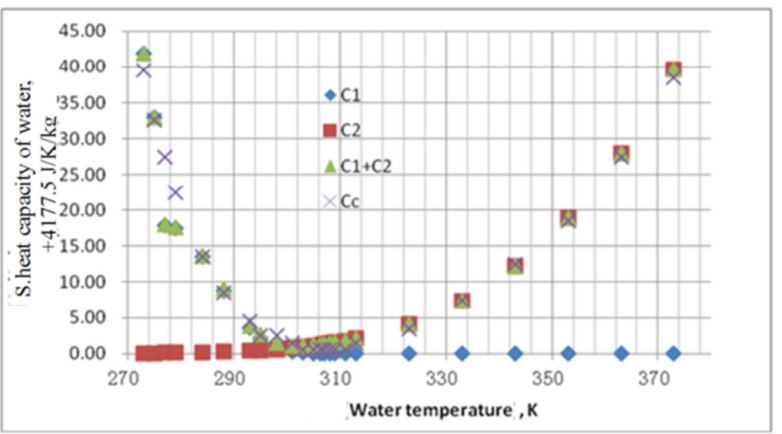

d

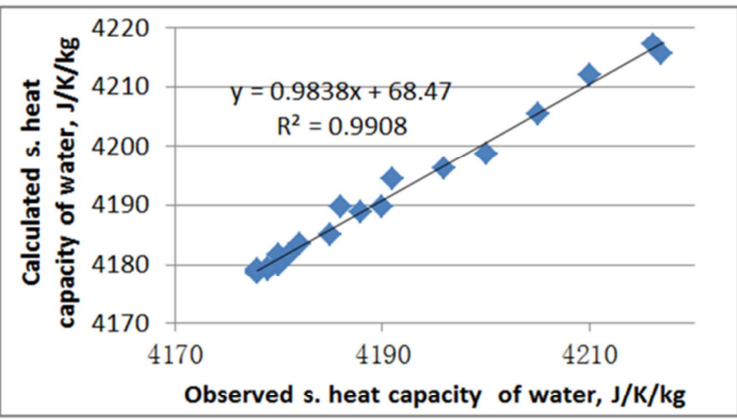

f

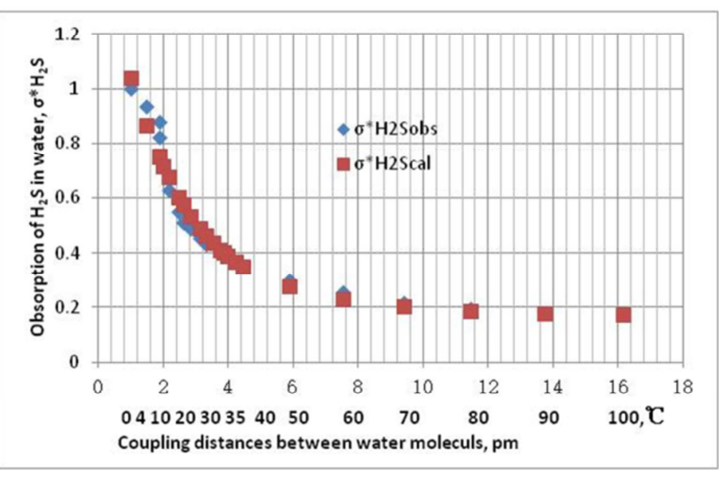

h

Figure 7. Calculated results for water characteristics. a) Coupling distances between water molecules with temperature; b) Relationship between the calculated and observed density of water from temperature $100^{\circ} \mathrm{C}$ to $-30^{\circ} \mathrm{C} ; \mathrm{c}$ ) Observed specific heat capacity of water between temperature $0-100^{\circ} \mathrm{C}$; d) Calculated specific heat capacity of water between temperature $0-100^{\circ} \mathrm{C}$ with calculation components; e) Calculated specific heat capacity of water between temperature $0-100^{\circ} \mathrm{C} ; \mathrm{f}$ ) Comparison between the calculated and observed data of specific heat capacity of water; $g$ ) Relationship between the absorption coefficients of $\mathrm{O}_{2}$ in water (calculated and observed) and water temperature-coupling distances between molecules.; h) Relationship between the absorption coefficients of $H_{2} S$ in water (calculated and observed) and water temperature-coupling distances between molecules. 
Table 3. Construction parameters of modeling water molecules under different temperature, $b$-Length of the edge of modeling water molecule, nm; $v$ - Volume of modeling water molecule, $\mathrm{nm}^{3}$; V-Total volume of modeling water molecules in $100 \mathrm{~g}, \mathrm{~cm}^{3}$; S. vol-specific volume, ml/100g; $\varepsilon$-Porosity ratio of water; $\rho$ - Water density, $\mathrm{g} / \mathrm{ml}$; $d_{c^{-}}$Coupling distances between water molecules, pm; Original length of edge of water molecule $=0.48017$ nm, Original volume of water molecule $=0.013047 \mathrm{~nm}^{3}$; Total volume of original water molecule in $100 \mathrm{~g}$ water $=43.61538 \mathrm{~nm}^{3}$.

\begin{tabular}{|c|c|c|c|c|c|c|c|c|c|c|}
\hline W.Temp, K & 173 & 203 & 243 & 253 & 263 & 273 & 275 & 277 & 279 & 284 \\
\hline W. Temp, ${ }^{\circ} \mathrm{C}$ & -100 & -70 & -30 & -20 & -10 & $0^{\circ} \mathrm{C}$ & $2{ }^{\circ} \mathrm{C}$ & $4^{\circ} \mathrm{C}$ & $6^{\circ} \mathrm{C}$ & $11^{\circ} \mathrm{C}$ \\
\hline Coef. for $b$ & 1.00008 & 1.0001 & 1.00065 & 1.00067 & 1.0008 & 1.001 & 1.0015 & 1.0018735 & 1.0018835 & 1.002 \\
\hline$b, \mathrm{~nm}$ & 0.48021 & 0.48022 & 0.48048 & 0.48049 & 0.48055 & 0.48065 & 0.48089 & 0.48107 & 0.48107 & 0.48113 \\
\hline$v, \mathrm{~nm}^{3}$ & 0.01305 & 0.01305 & 0.01307 & 0.01307 & 0.01308 & 0.01309 & 0.01311 & 0.01312 & 0.01312 & 0.01313 \\
\hline$V, \mathrm{~nm}^{3}$ & 43.6258 & 43.6285 & 43.7005 & 43.7031 & 43.7201 & 43.7464 & 43.8119 & 43.8610 & 43.8623 & 43.8776 \\
\hline$S$. vol. & 101.474 & 101.480 & 101.647 & 100.648 & 100.189 & 100.016 & 100.006 & 100.003 & 100.006 & 100.041 \\
\hline porosity, $\varepsilon$ & 2.326 & 2.326 & 2.326 & 2.303 & 2.2916 & 2.28628 & 2.28262 & 2.28 & 2.28 & 2.28 \\
\hline$d_{c}, \mathrm{pm}$ & 0.07683 & 0.09603 & 0.62422 & 0.64343 & 0.76827 & 0.96034 & 1.44051 & 1.79920 & 1.80880 & 1.92068 \\
\hline
\end{tabular}

\begin{tabular}{|c|c|c|c|c|c|c|c|c|c|c|}
\hline W.Temp, K & 284 & 303 & 306.3 & 309 & 323 & 333 & 343 & 353 & 363 & 373 \\
\hline W. Temp, ${ }^{\circ} \mathrm{C}$ & $11^{\circ} \mathrm{C}$ & $30^{\circ} \mathrm{C}$ & $33.3^{\circ} \mathrm{C}$ & $36^{\circ} \mathrm{C}$ & $50^{\circ} \mathrm{C}$ & $60^{\circ} \mathrm{C}$ & $70^{\circ} \mathrm{C}$ & $80^{\circ} \mathrm{C}$ & $90^{\circ} \mathrm{C}$ & $100^{\circ} \mathrm{C}$ \\
\hline Coef. for $b$ & 1.00200 & 1.00332 & 1.00361 & 1.00398 & 1.00589 & 1.00754 & 1.00940 & 1.01146 & 1.01373 & 1.01617 \\
\hline$b, \mathrm{~nm}$ & 0.48113 & 0.48177 & 0.48190 & 0.48208 & 0.48300 & 0.48379 & 0.48468 & 0.48567 & 0.48676 & 0.48793 \\
\hline$v, \mathrm{~nm}^{3}$ & 0.01313 & 0.01318 & 0.01319 & 0.01320 & 0.01328 & 0.01334 & 0.01342 & 0.01350 & 0.01359 & 0.01369 \\
\hline$V, \mathrm{~nm}^{3}$ & 1.00601 & 1.01000 & 1.01086 & 1.01199 & 1.01777 & 1.02279 & 1.02847 & 1.03478 & 1.04175 & 1.04929 \\
\hline$S$. vol. & 100.0409 & 100.4374 & 100.5227 & 100.6351 & 101.2106 & 101.7095 & 102.2738 & 102.9012 & 103.5947 & 104.3449 \\
\hline porosity, $\varepsilon$ & 2.28 & 2.28 & 2.28 & 2.28 & 2.28 & 2.28 & 2.28 & 2.28 & 2.28 & 2.28 \\
\hline Den. $\rho, \mathrm{g} / \mathrm{ml}$ & 0.99960 & 0.99565 & 0.99480 & 0.99369 & 0.98804 & 0.98320 & 0.97777 & 0.97179 & 0.96531 & 0.95836 \\
\hline$d_{c}, \mathrm{pm}$ & 1.92068 & 3.19025 & 3.46299 & 3.82215 & 5.65640 & 7.24096 & 9.02719 & 11.00549 & 13.18258 & 15.52677 \\
\hline
\end{tabular}

\subsubsection{The Expansibility and Compressibility of Water}

The structure of water molecule (with the edge length of $b=0.48017 \mathrm{~nm}$ ) related with the quantum mechanics, but not macro dynamics. Therefore the volume of a water molecule does not related with macro parameters temperature and pressure, but the distances between the coupling molecules $\left(d_{c}\right)$ are influenced by temperature and pressure. The $d_{c} \approx 0.96$ $\left(0^{\circ} \mathrm{C}\right)-15.53 \mathrm{pm}\left(100^{\circ} \mathrm{C}\right)$ under a standard atmospheric pressure (Table 3). Therefore both the expansibility and compressibility of water are the least one among the liquid substances, except mercury [3].

For example, under temperature $t=20^{\circ} \mathrm{C}$, and the standard atmospheric pressure: the expansibility $\left.\beta_{t}=\left(1 / v_{t}\right)\left(\mathrm{d} v_{t} / \mathrm{d} t\right)\right)$ for water $\beta_{t}=0.21 \times 10^{-3}$; for sulphuric acid $(100 \%) \beta_{t}=0.56 \times 10^{-3}$, for aniline $\beta_{t}=0.85 \times 10^{-3}$.

The compressibility $(\zeta=-(1 / v)(\mathrm{d} v / \mathrm{d} p))$ : for water $\zeta=0.45$ $\mathrm{GPa}^{-1}$ [13], for ethylalcohol $\zeta=1.23 \mathrm{GPa}^{-1}$ [3].

\subsection{Specific Heat Capacity of Water}

The structure of water is an electric coupling net of water molecules. Any molecule pyramid is coupled with 4 other molecule pyramids. Moreover, there are frequent recombination of the frame (in time scale of $10^{-15} \mathrm{~s}$ ) associated with the exchange of positions of on/ leave the frame in the liquid water. Any temperature change at one point on the net will distributed to the surround environment with energy expenditure. Thereafter, the specific heat capacity of water is as big as $4217 \mathrm{~J} \cdot \mathrm{kg}^{-1} \cdot \mathrm{K}^{-1}$, which is much bigger than that of $482 \mathrm{~J} \cdot \mathrm{kg}^{-1} \cdot \mathrm{K}^{-1}$ for usual metal and that of 2 000, $2030,2000 \sim 2010 \mathrm{~J} \cdot \mathrm{kg}^{-1} \cdot \mathrm{K}^{-1}$ [3, f. n. 2] for oils. The solid state of water ice has degrees of freedom of three-dimensional vibration, and the liquid water has additional three-dimensional rotation and associated with the exchange of positions of on/ leave the frame in process of reconstruction of frame. So the specific heat capacity of liquid water is more than that of for solid water ice in $2^{+}$ times. The specific heat capacity for solid water ice under the standard atmospheric pressure and $0^{\circ} \mathrm{C}$ is $1960 \mathrm{~J} \cdot \mathrm{kg}^{-1} \cdot \mathrm{K}^{-1}[4$, $11]^{2}$, which is $1 / 2.12$ in comparison with that of liquid water under the same condition. The specific heat capacity of ice is rapidly decreased with decrease of temperature as 2.0 2.1 $\mathrm{J} \cdot \mathrm{g}^{-1} \cdot \mathrm{K}^{-1}$ for $-26 \sim-{ }^{\circ} \mathrm{C}^{-1}$; and $2.05,1.00$, and $0.15 \mathrm{~J} \cdot \mathrm{g}^{-1} \cdot \mathrm{K}^{-1}$ [3] under temperature of $-10,-160$, and $-250^{\circ} \mathrm{C}$, respectively. The ions in dissolved $\mathrm{NaCl}$ salt water may co-attract each other with the "free water molecules" and suppress the "free water molecules" return to the frame, so the frozen temperature is lower than that of the pure water of $0^{\circ} \mathrm{C}$ under the same pressure condition. All these confirm the existence of "free molecule" in the liquid water structure. It is very possible that being related with latent energy transforming, the frozen and melting ice process are started from some-what at the boundary or very small points in the centers of the liquid water with low temperature as the nucleus of condensation. The coupling force is co-attraction force, so the process of ice melting with decrease of volume would be easier than the process of water frozen with increase of volume. Therefore, the subcooled water may form under some special uniform conditions under temperature below $0^{\circ} \mathrm{C}$.

The specific heat capacity of water has also a special changing process in relation with changing temperature (Figure 7c). The coupling distance is $d_{c} \approx 1 \mathrm{pm}$, and maximum of $15.5 \mathrm{pm}$ under water temperature 0 , and $100^{\circ} \mathrm{C}$, respectively. The minimum of changes of the specific heat of water is located by $d_{c} \approx 3 \sim 4 \mathrm{pm}$ when the water temperature is between $30 \sim 40^{\circ} \mathrm{C}$ (Table 3). It is more difficult to increase the water temperature by heating, but easier to decrease the water temperature by cooling, when the water temperature is above $40^{\circ} \mathrm{C}$, and contrary, it is difficult to decrease the water

2 http://www.iun.edu/ cpanhd/C101webnotes/matter-and-energy/specificheat.html; 
temperature by cooling and easier to increase the water temperature by heating when the water temperature is below $30^{\circ} \mathrm{C}$. It means that in this interval for changing temperature need minimum of energy. The fact, that human body temperature is about $37^{\circ} \mathrm{C}$ is very possible related with the adaption of human to the environment for decreasing expenditure of energy. It is possible that the variation characters of the averaged thermal dynamic movement of water molecules are different in the above mentioned two temperature intervals.

The Maxwell distribution equation for the speed of thermal molecule movement is as (Figure 6) [13]:

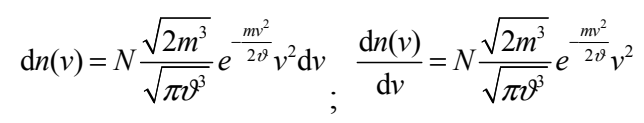

Where $N$ is a constant, $v$ is the speed of molecule movement, $n(v)$ is the averaged kinetic energy of molecule, $m$ is the mass of the molecule, $\vartheta$ is a parameter of direct ratio to the absolute temperature K. Figure 6 is the sketch of the Maxwell distribution, where the abscissa is movement speed $v$, and the ordinate is $y$ :

$$
\frac{\mathrm{d} n(v)}{\mathrm{d} v}=y=\alpha v^{2} e^{-\beta v^{2}}, \quad \text { where } \alpha=0.173, \beta=0.000015 \text { with }
$$

Maximum of y at $v_{H}=\sqrt{2 \vartheta / m}$

It shows that the $y$ rapidly increase with increase of $v$ and reach the maximum of $v_{H}$ (most possible value of $y$,), then decrease to 0 . The averaged speed is $v_{H}=\sqrt{2 \vartheta / m}$. The averaged $v^{2}$, which is proportional to kinetic energy is $\overline{v^{2}}=3 \vartheta / m$. The ratio of them is: $\overline{v^{2}}: \bar{v}: v_{H}=\sqrt{3}: \sqrt{8 / \pi}: \sqrt{2}$.

The coupling distance between water molecules $d_{c}$ increases with increase of temperature (Table 2). Take non-dimensional parameters $d=d_{c(T)} / d_{c 0}$, where $d_{c(T)}$ and $d_{c 0}$ are the coupling distances at temperature $\mathrm{T} \mathrm{K}$ and at $0^{\circ} \mathrm{C}$, separately. Really, the coupling distance $d$ is the averaged distance in "macro scale of time", when the attracting force between the proton "+" of the first water molecule and the "-." electron cloud point of the second coupling water molecule may be balanced by the repulsive force between the return electron to the coupling endpoint of the first molecule and the electron cloud point of the second molecule. This process is a dynamic balance with high frequency of vibration in time scale of fs., associated with temperature vibration of molecules of the two molecules with certain frequency, but averaged in "macro scale of time". The electric force is inverse ratio to the squire of distance. The thermal vibration of molecules is direct ratio to the vibration frequency and squire of the vibration amplitude, which may be proposed as $(d-1)^{2}$. So we may take the specific heat $C$ is contributed by three components as:

$$
\begin{aligned}
& C=C_{0}+C_{1}+C_{2} \quad ; \quad \text { where } \quad C_{1}=\alpha_{1} d^{2} e^{-\beta_{1} d^{2}}, \\
& C_{2}=\alpha_{2}(d-1)^{2} e^{-\beta_{2}(d-1)^{2}}, \\
& \text { and } C_{0}=4 \quad 177.5 \mathrm{~J} \cdot \mathrm{kg}^{-1} \cdot \mathrm{K}^{-1} ; \alpha_{1}=79 \mathrm{~J} \cdot \mathrm{kg}^{-1} \cdot \mathrm{K}^{-1}, \beta_{1}=0.73 ; \\
& \alpha_{2}=0.173 \mathrm{~J} \cdot \mathrm{kg}^{-1} \cdot \mathrm{K}^{-1}, \beta_{2}=0.000015 \text {. }
\end{aligned}
$$

The calculated and observed data are shown in Figure $7 d$, 7e. In Figure $7 \mathrm{~d}$ we can see the contribution of each component of $C_{1}$ and $C_{2}$. The $C$ has very small variation in section $30 \sim 40^{\circ} \mathrm{C}\left(d_{c}=3 \sim 4 \mathrm{pm}\right)$ with variation of temperature and has minimum value. The comfortable temperature for human is $37^{\circ} \mathrm{C}$, at this minimum of consuming energy for keeping this temperature may be an adaption result on environment. There are high correlation coefficients between the calculated and observed data. Such specific characteristics are of interest and worth to be further study.

\subsection{The Electric and Thermal Conductivity}

\subsubsection{The Electric Conductivity of Water}

The pure water has very high electric resistivity as $1.82 \times 10^{5} \Omega \cdot \mathrm{m}$. The observed extreme low value of electric conductivity of water was $0.0547 \mathrm{~S} \cdot \mathrm{cm}^{-1}\left(25^{\circ} \mathrm{C}\right)[14,15, \mathrm{f} . \mathrm{n}$. 2]. According to the structure model of water molecule in this paper, the water molecules are coupled each other with "+" ".-" endpoints, only $1 / 11$ molecules are in the cages and coupling with the frame points with double electrons. Some data show that the characteristics of water ion only appear/ or hide during 200 fs (femtosecond) [11].

\subsubsection{The Thermal Conductivity}

The thermal conductivity is $0.561\left(0^{\circ} \mathrm{C}\right), 0.673\left(80^{\circ} \mathrm{C}\right)$ $\mathrm{W} \cdot \mathrm{m}^{-1} \cdot \mathrm{K}^{-1}$; which is higher than that of switch oil for transformer of $0.136\left(0^{\circ} \mathrm{C}\right), 0.127\left(100^{\circ} \mathrm{C}\right)$ on $4 \sim 5$ times, and is the highest one among all the liquid substances [3]. This closely related with the stereo cage net frame structure of water. One water molecule is closely coupling with 4 other molecules and frequently exchange with "free molecule" and reconstruction of frame. All the specific characters of extreme low electric conductivity, and very high thermal specific heat can be reasonable explained by the above stereo cage net frame of water structure.

\subsection{Water as a Dissolvent}

Water is a very good dissolvent. It can dissolve many substances in it with relatively large solubility. Liquid water molecules construct three-dimensional ZHTVS (Zigzag Hexagonal Tunnel-Vacancy System), where can store various substances. The porosity ratio of water is $\geq 2.28$ during $0-100^{\circ} \mathrm{C}$. The discussions on the solubility of liquid water for some gases and solid maters as samples will be shown as follows:

\subsubsection{Dissolved gas}

The density of gases in the atmosphere has the order of magnitude $10^{-3} \mathrm{~g} \cdot \mathrm{cm}^{-3}$, which is less than that of water on 3 orders of magnitude. The mass of dissolved gases is less than that of water molecule on 3 orders of magnitude. Thereafter, the gases, if they do not make chemical reaction with water, or have no electric polarity, usually have small influences on the volume and temperature of water. As examples, we will discuss the dissolution characteristics of oxygen and hydrogen sulfide in water. These two gases have important effects for water environments.

i. Dissolved oxygen

The fact that there is dissolved oxygen in water indicates that there has certain space for store gas. The density of 
oxygen under 1 standard atmosphere pressure at $0^{\circ} \mathrm{C}$ is 1.429 $\mathrm{g} \cdot \mathrm{L}^{-1}$. The saturated absorption coefficient of oxygen in volume is $\sigma=0.04889$, so there may be absorbed 0.04889 $\mathrm{cm}^{3}$ oxygen in water of $1 \mathrm{~cm}^{3}(4.9 \approx 5 \mathrm{~mL}$ oxygen dissolved in $100 \mathrm{~mL}$ water), for mass is $q=0.006945$, so there may be absorbed $0.006945 \mathrm{~g}$ oxygen in water of $100 \mathrm{~g}$. The saturated absorption coefficient of oxygen decreases in relation with increase of water temperature, because the decreasing process of oxygen density is larger than that of water.

$$
\sigma_{O}^{*}=\sigma_{O, t} / \sigma_{O, 0}=\sigma_{O, 00}+\alpha_{O, 1} \sqrt{\mathrm{d}_{\mathrm{t}}^{*}} \operatorname{EXP}\left(-\beta_{0,1} \sqrt{\mathrm{d}_{\mathrm{t}}^{*}}\right)+\alpha_{O, 2}\left(\mathrm{~d}_{\mathrm{t}}^{*}+\mathrm{d}_{00}\right) \operatorname{EXP}\left(-\beta_{O, 2}\left(\mathrm{~d}_{\mathrm{t}}^{*}+\mathrm{d}_{00}\right)\right)+\alpha_{O, 3} \delta\left(\mathrm{d}_{4} / \mathrm{d}_{\mathrm{t}}^{*}+\mathrm{d}_{00}\right) \operatorname{EXP}\left(\beta_{O, 3}\left(\mathrm{~d}_{4} / \mathrm{d}_{\mathrm{t}}^{*}+\mathrm{d}_{00}\right)\right)
$$

Where $\sigma_{0}{ }^{*}$-non-dimensional parameter of saturated absorption coefficient of oxygen: $\sigma_{\mathrm{o}}{ }^{*}=\sigma_{\mathrm{o}, \mathrm{t}} / \sigma_{\mathrm{o}, 0}$

$\sigma_{\mathrm{o}, 0}=0.048$ 89. The $\sigma_{\mathrm{o}, 00}=0.34 \alpha_{\mathrm{o}, 1}=1.8, \alpha_{\mathrm{o}, 2}=1.82, \alpha_{\mathrm{o}, 3}=10$, $\beta_{\mathrm{o}, 1}=1.7, \beta_{\mathrm{o}, 2}=1.4, \beta_{\mathrm{o}, 3}=3.2$, are empirical constants. The Kronecker Sign $=1\left(\mathrm{t}>15^{\circ} \mathrm{C}\right)$ and $=0\left(\mathrm{t} \leq 15^{\circ} \mathrm{C}\right) . \mathrm{d}_{\mathrm{t}}{ }^{*}=\mathrm{d}_{\mathrm{t}} / \mathrm{d}_{0}$ is the non- dimensional parameter of the coupling distance between water molecules at temperature $t$ in ratio to that of at $\mathrm{t}=0^{\circ} \mathrm{C}$. We have constants: $\mathrm{d}_{00}=0.47, \mathrm{~d}_{4}=1.8435$ (the $\mathrm{d}$ at temperature $\mathrm{t}=4^{\circ} \mathrm{C}$ ).

Both the calculated and observed data are presented in Figure 7f, which shows that they have good coincidence.

ii. Dissolved hydrogen sulfide $\left(\mathrm{H}_{2} \mathrm{~S}\right)$

The molecule $\mathrm{H}_{2} \mathrm{~S}$ possess electric moment. So dissolved
$\mathrm{H}_{2} \mathrm{~S}$ gas may partly couple each other and influence on the coupling distances of liquid water structure. The density of $\mathrm{H}_{2} \mathrm{~S}$ at $0^{\circ} \mathrm{C}$ under 1 standard atmosphere pressure is 1.593 $\mathrm{g} / \mathrm{L}$. The boiling point of $\mathrm{H}_{2} \mathrm{~S}$ is $-60.4^{\circ} \mathrm{C}$. The saturated absorption coefficient of hydrogen sulfide is $\sigma=4.670$ [15], so there may be absorbed $4.670 \mathrm{~cm}^{3}$ hydrogen sulfide in water of $1 \mathrm{~cm}^{3}$ (4.9 mL oxygen dissolved in $100 \mathrm{~mL}$ water), which is 95.5 times more than that of for oxygen. The $q=0.7066 \mathrm{~g}$ for saturated $\mathrm{H}_{2} \mathrm{~S}$ (namely, there are $0.7066 \mathrm{~g} \mathrm{H}_{2} \mathrm{~S}$ gas dissolve in $100 \mathrm{~g}$ liquid water. It means that $\mathrm{H}_{2} \mathrm{~S}$ gas may be strongly compressed gaseous state in liquid water frame, but not in atmosphere. For fitting the observed results may use the following equation:

$$
\sigma_{H_{2} S}^{*}=\sigma_{H_{2} S, t} / \sigma_{H_{2} S, 0}=\sigma_{H_{2} S, 00}+\alpha_{H_{2} S, 1}\left(\mathrm{~d}_{\mathrm{t}}^{*}\right)^{2 / 3} \operatorname{EXP}\left(-\beta_{H_{2} S, 1}\left(\mathrm{~d}_{\mathrm{t}}^{*}\right)^{2 / 3}\right)+\alpha_{H_{2} S, 2}\left(\mathrm{~d}_{\mathrm{t}}^{*}+\mathrm{d}_{00}\right) \operatorname{EXP}\left(-\beta_{H_{2} S, 2}\left(\mathrm{~d}_{\mathrm{t}}^{*}+\mathrm{d}_{00}\right)\right)
$$

where $\sigma^{*}{ }_{\mathrm{H} 2 \mathrm{~S}}$-non-dimensional saturated absorption coefficient of $\mathrm{H}_{2} \mathrm{~S}$, the ratio of $\sigma_{H 2 S}$ at $t^{\circ} \mathrm{C}$ to that of $\sigma_{H 2 S, 0}=0.96831$ at $0^{\circ} \mathrm{C}$; $\sigma_{H 2 S, 00}=0.17, \alpha_{H 2 S, 1}=1.8, \alpha_{H 2 S, 2}=1.82 ; \beta_{H 2 S, 1}=1.23, \beta_{H 2 S, 2}=1.4$; $d_{00}=0.47$ are empirical constants.

Both the calculated and observed data are presented in Figure $7 \mathrm{~g}$, which shows that they have good coincidence.

\subsubsection{Solubility of Inorganic Substances}

$\mathrm{The} \mathrm{NaCl}$ and $\mathrm{KCl}$ are inorganic substances. Their crystals may easily be dissolved in liquid water. The formula weight of $\mathrm{H}_{2} \mathrm{O}, \mathrm{NaCl}$, and $\mathrm{KCl}$ are $18.014,58.4428$, and 74.551; separately. The Avogadro constant for each mol substances has particles of $6.0221367 \times 10^{23}$. If the $35.58 \mathrm{~g}(0.61 \mathrm{~mol})$ $\mathrm{NaCl}$ and $28.08 \mathrm{~g}(0.37 \mathrm{~mol}) \mathrm{KCl}$ mixed with $100 \mathrm{~g}(5.55 \mathrm{~mol})$ water may make the saturated solution for $\mathrm{NaCl}$ and $\mathrm{KCl}$ at $0^{\circ} \mathrm{C}$. Therefore, according to these data we may calculate the ratio of particles number in the saturated solution of $\mathrm{NaCl}$ (or $\mathrm{KCl}$ ) are about 9 (or 15) water molecules enclosed $1 \mathrm{NaCl}$ (or $\mathrm{KCl}$ ) molecule, separately. The $\mathrm{NaCl}$ and $\mathrm{KCl}$ can be dissolved in liquid water molecule frame does not unlimited. The excess $\mathrm{NaCl}$ and $\mathrm{KCl}$ may maintain their solid crystal, staying out of the liquid solution. Similarly, the liquid water may infiltrate into the salt crystals. Usually we need mix the salt with water for dissolving salt, and the un-dissolved solid salt will settle down to the bottom. The atomic number of
Hydrogen, $\mathrm{Na}$, and $\mathrm{K}$ are 1, 11, and 19, separately. The increase of protons in atoms of $\mathrm{Na}, \mathrm{K}$ may increase the repulsive force with hydrogen atoms and may increase the coupling distance between the water molecules (like virtual increase of temperature). As a matter of fact, when the $\mathrm{NaCl}$ (about $\left.26 \mathrm{~g}, 12.00924 \mathrm{~cm}^{3}\right)$ dissolved into fresh water $(74 \mathrm{~g}$, $\left.74.01184 \mathrm{~cm}^{3}\right)$, the volume of saturated salt water $(82.84386$ $\mathrm{cm}^{3}$ ) increase $11.9 \%$ than that of the pure (fresh) water, which means that the water frame increases its total volume, in one hand, and in the other hand the volume of solid $\mathrm{NaCl}+$ liquid water $\left(12.00924+74.01184=86.02108 \mathrm{~cm}^{3}\right)$ is decrease to $82.84386 \mathrm{~cm}^{3}$ (decrease on $3.7 \%$ ), which means the molecules of $\mathrm{NaCl}$ penetrate into the vacancy cage frame of fresh water. The salt water is enclosed by the molecules of fresh water (Table 4). The freezing point of salt water is lower than that of fresh water. The "free water molecules" will be attracted by $\mathrm{NaCl}$ ions and more difficult to return to the frame in comparison with fresh water. We should put the salt water into refrigerator under $-18^{\circ} \mathrm{C}$. The freezing salt water increase $1 / 11$ of the original volume of fresh water $(74.011 / 11=6.73$ $\mathrm{cm}^{3}$ ), which means the salt water increase its volume of $63.73 / 82.84 \times 100=8.12 \%$ after freeze. These experiment results are shown in Table 4.

\begin{tabular}{|c|c|c|c|c|c|c|c|c|c|c|}
\hline I & II & III & IV & V & VI & VII & VIII & IX & $\mathbf{X}$ & XI \\
\hline 2.165 & 26 & 74 & 1.20709 & 12.00924 & 74.01184 & 86.02108 & 82.84386 & 89.57221 & 6.72835 & $1 / 11$ \\
\hline
\end{tabular}

Table 4. Volume variation of saturated solution of $\mathrm{NaCl}$.

I: Density of solid $\mathrm{NaCl}, \mathrm{g} \cdot \mathrm{cm}^{-3}$; II: Weight of solid $\mathrm{NaCl}$ to be dissolved in pure water for saturation, g; III: Weight of pure water as solvent, g; IV: Density of saturated salt water, $\mathrm{g}^{\cdot} \mathrm{cm}^{-3} ; \mathrm{V}$ : Volume of solid $\mathrm{NaCl}, \mathrm{cm}^{3}$; VI: Volume of pure water as solvent, $\mathrm{cm}^{3}$; VII: Volume of solid $\mathrm{NaCl}+$ pure water; $\mathrm{cm}^{3} ; \mathrm{VIII}: \mathrm{Volume}$ of saturated salt water of $100 \mathrm{~g}, \mathrm{~cm}^{3}$; VII- VIII $=3.17722 \mathrm{~cm}^{3} ; \mathrm{NaCl}$ molecules transform into $\mathrm{Na}^{+}+\mathrm{Cl}^{-}$ion state and get into water porosity vacant space, decrease original (solid $\mathrm{NaCl}+$ pure water) volume and expand water structure frame (increase coupling distance between water molecules); solid state salt disappears, liquid system (salt water) increases volume on $8.83202 \mathrm{~cm}^{3},(10.66 \%)$; IX: After icing salt water liquid system transforms into solid state, increasing volume; X: Volume of salt water ice - volume of salt water liquid; XI: $(X / V I) \approx 1 / 11$, which conforms to the model. (The experiments performed in Nanjing during December 2015-January 2016.) 


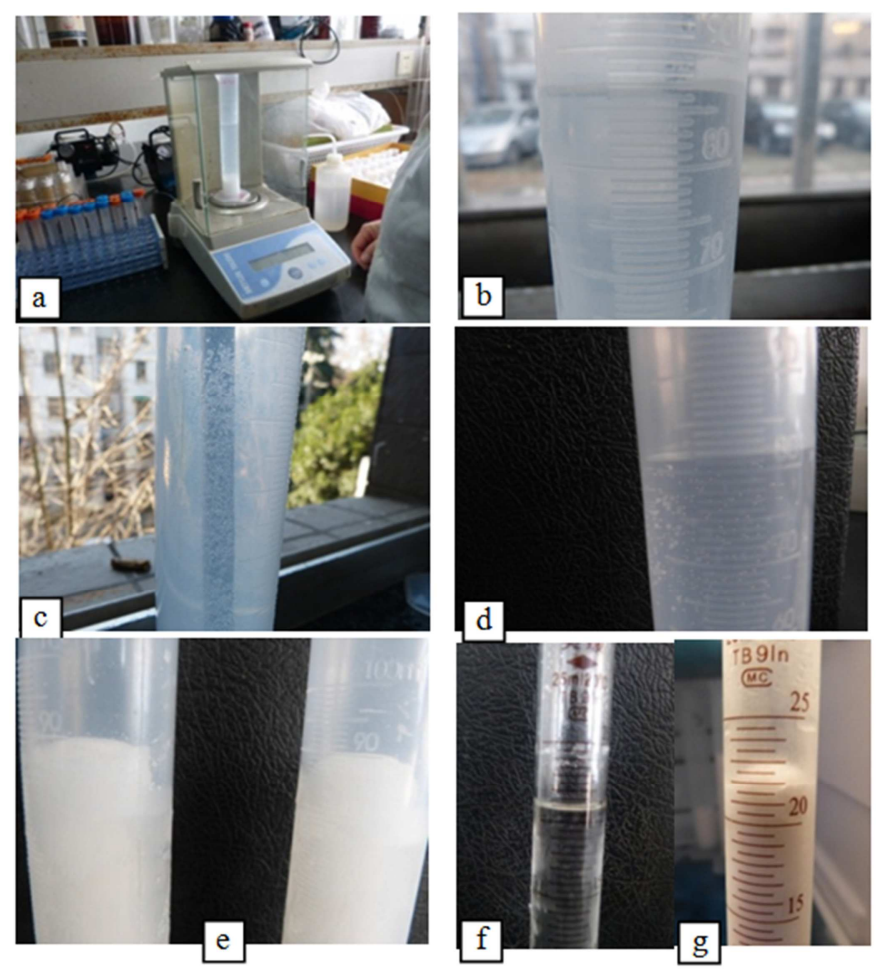

Figure 8. Experiment for freezing saturated solution of $\mathrm{NaCl}$; a) Add $76 \mathrm{~g}$ deionized water to $24 \mathrm{~g} \mathrm{NaCl}$ (the white solid $\mathrm{NaCl}$ is at the bottom and separate with water) in measuring cylinder; b) The crystal of $\mathrm{NaCl}$ decreasing after disturbance, releasing heat, and abundant bubbles, which were dissolved in water; The total volume of the saturated solution of $100 \mathrm{~g} \mathrm{NaCl} \mathrm{occupied} \mathrm{about} 86 \mathrm{ml} \mathrm{at} 20^{\circ} \mathrm{C}$; c) The abundant bubbles indicate that there are porosities in liquid water; $d$ ) The $100 \mathrm{~g}$ saturated solution of $\mathrm{NaCl}$ without color has volume of about $83 \mathrm{~cm}^{3}$; e) which froze after $24 \mathrm{~h}$ in the refrigerator keep under $-18^{\circ} \mathrm{C}$, increased volume to about $89.5 \mathrm{ml}$ (close to the theoretical volume of $89.6 \mathrm{ml}$ ) with white color as the crystal of $\mathrm{NaCl}$, which indicated that the molecules of $\mathrm{NaCl}$ were surrounded by the water molecules (about 9 water molecules to $1 \mathrm{NaCl}$ molecule, according to the theoretical calculation); f) Saturated transparent NaCl solution of $20.8 \mathrm{ml}$; g) After frozen saturated solution became white color with volume of $22.5 \mathrm{ml}$ (good according with the theoretical volume). The experiments performed during December 2015- January 2016

The key points of the experiment are as follows:

(1). Prepare chemically pure crystal $\mathrm{NaCl}$ of $26.0 \mathrm{~g}$ and $26.3 \mathrm{~g}$ for experiment and then add deionized water to $100 \mathrm{~g}$. There is about $23 \mathrm{~mL}$ with solid salt at the bottom of the test tube, and the water level is about 86 $\mathrm{cm}^{3}$ There only a little salt has been dissolved into the water (Figure 8a,b).

(2). Mix the salt- water, the test tube is warming, indicating there is a heat release process along with the dissolution of $\mathrm{NaCl}$ into water. There appear a lot of air bubbles in the tube and coming out to the water surface. The $\mathrm{NaCl}$ molecule in water posses electricity "+" "-" ion characteristics and may combine with water molecules by Coulomb force and drive out the air gas, which has less combining force with water molecules, from the tunnel vacancy of water structure frame, and release the chemical energy into thermal energy (Figure $8 \mathrm{c})^{3}$.

(3). Continuously mix the salt water. The total volume of the salt water decreases from 90 (the salt does not compacted) $\mathrm{cm}^{3}$ (23) (indicating with white $\mathrm{NaCl}$ crystal of $23 \mathrm{~cm}^{3}$ at the bottom), 88 (9), 87 (1), 87 (0.5), $87(0.0), 85,84,83 \mathrm{~cm}^{3}$ (it should be $82.84 \mathrm{~cm}^{3}$ according to the theoretical- careful experiment). (Figure 8d).

\footnotetext{
3 L1060764.MP4, L1060753.MP4; Please ask the authors for videos by email.
}

(4). It is very difficult for freezing the saturated salt water [18], indicating the "free water molecules" in the frame may electrically combine with the $\mathrm{NaCl}$ ions and in difficulty to become a "frame structure molecules". We should put the tube into refrigerator under temperature of $-18^{\circ} \mathrm{C}$ over night. The freeze salt water appears white color, as the same with the white $\mathrm{NaCl}$ crystal, indicating that all the $\mathrm{NaCl}$ molecules are enclosed by water molecules and distributed in the whole water/ ice vacancy. Because the thermal conduction is mostly by thermal exchange pass through the tube wall, so the ice is appears along the tube wall firstly and the internal waters freeze latter, and appears a hemispherical head in the tube center (Figure 8e, near $90 \mathrm{~cm}^{3}$ ). Figure $8 \mathrm{f}$ indicating the saturated salt water of $20.8 \mathrm{~cm}^{3}$ increase its volume of $22.5 \mathrm{~cm}^{3}$ (Figure $8 \mathrm{~g}$ ). For example, there is fresh water of $20.8 \times 74.01184 / 82.43 \quad 86=18.5825 \mathrm{~cm}^{3}$ in saturated $\mathrm{NaCl}$ solution of $20.8 \mathrm{~cm}^{3}$. The increased volume after freeze would be $20.8+18.5825 \times 1 / 11$ $=22.49 \mathrm{~cm}^{3}$, which is close to $22.5 \mathrm{~cm}^{3}(22 \sim 23$ convex head, Figure 8g).

(5). All above results indicate that the existence of tunnel vacancy of water frame structure is a real fact of high possibility. The existence of free water molecules, being electric attracted with the frame water molecules 
in the tunnel vacancy of water frame structure is the necessary and sufficient condition for existence of liquid state of water.

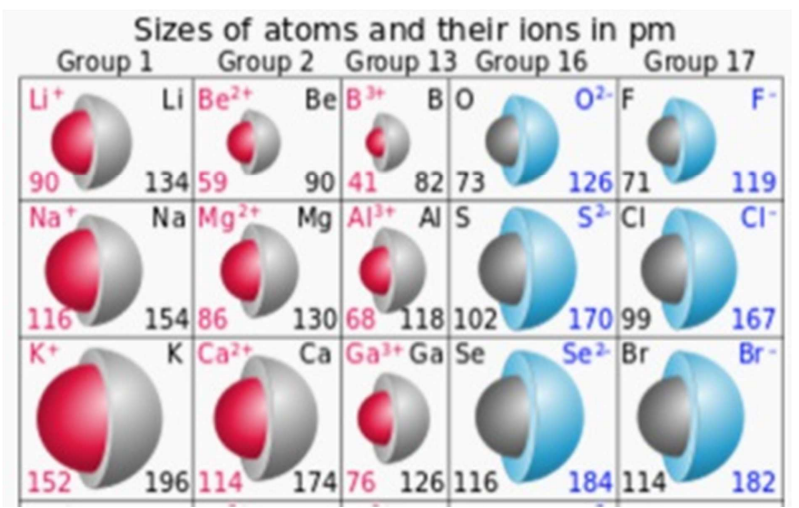

Figure 9. Sizes of certain atoms and their ions in pm [15].

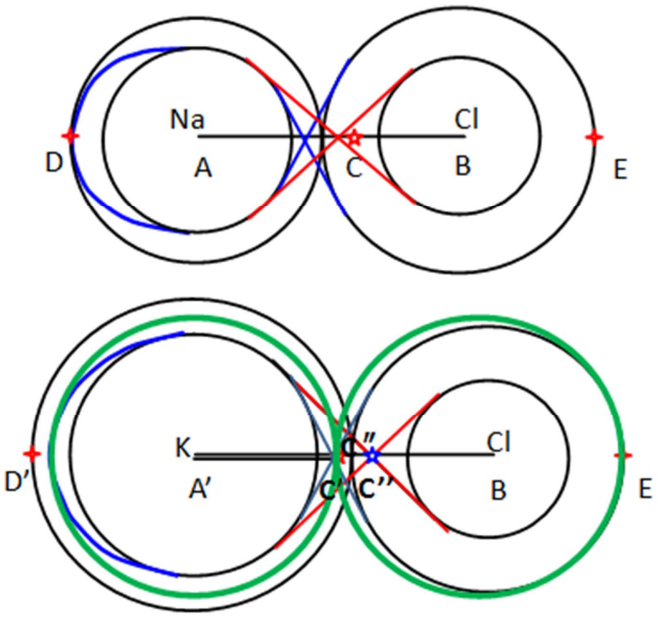

Figure 10. Modeling sketch of the ions/molecules of $\mathrm{NaCl}$ and $\mathrm{KCl}$ in water on relative scale as in Figure 9.

\subsubsection{Variation of Saturated Solubility of $\mathrm{NaCl}$ and $\mathrm{KCl}$ in Relation with Temperature Variation}
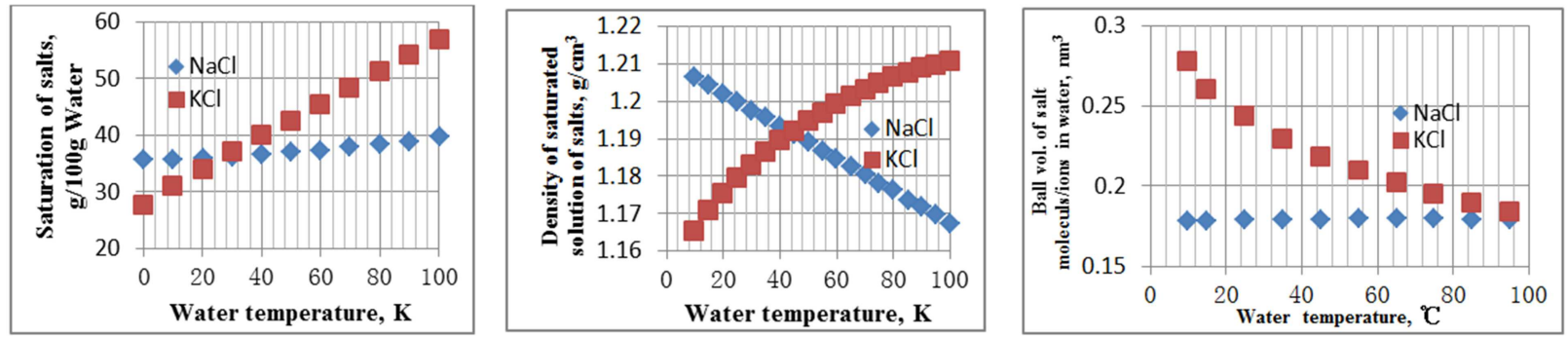

Figure 11. Variation of saturation, dencity of saturated solution and the spherical volumes of the moleculs/ions of NaCl and KCl with water temperature.

Both the $\mathrm{NaCl}$, and $\mathrm{KCl}$ are inorganic salt, but they have big differences in the regular pattern of the dissolving characters with the variation of temperature [16, 17]. According to the recent data ${ }^{4}$ (Figure 9) we can have Figure 10 in proportion scale. The mass center of molecule $\mathrm{NaCl}$ is located in the region of "-" ion of $\mathrm{Cl}$. According to the law of conservation of momentum: $A C \times w_{N}=C B \times w_{C}$; (where $w_{N}$ and $w_{C}$ are the atomic weight of $\mathrm{Na}$ and $\mathrm{Cl}$, separately). $A C+C B=0.321 \mathrm{~nm}, A C=0.19473 \mathrm{~nm}, C B=0.12627 \mathrm{~nm}$, $C D=0.34873 \mathrm{~nm}, C E=0.29327 \mathrm{~nm}$. Because the values of the rotation radii around atoms of $\mathrm{Na}$ and $\mathrm{Cl}$ are very similar, so the electrons can fly arbitrarily around any atoms and transform from one to another atom easily with trajectory form of " $\infty$ ". The whole $\mathrm{NaCl}$ molecule can rotate around its mass center $\mathrm{C}$ in three dimension space and form a sphere with volume of $0.17765 \mathrm{~nm}^{3}$, which appears distinct electric characteristics of $\mathrm{Na}^{+}$("+" ion) and $\mathrm{Cl}^{-}$(“-“ ion), because atom $\mathrm{Na}$ has 11 electron ( 1 electron on the outer third orbit, which is easy to fly away with more possibility and appear "+" electricity endpoint) and $\mathrm{Cl}$ has 17 electrons (7 electrons on the outer third orbit, where is easy to accept other 1 electron and appear "_." electricity endpoint). This kind structure of $\mathrm{NaCl}$ in water is less related with the temperature.

$4 \mathrm{https} / / /$ en.wikipedia.org/wiki/Ionic_radius; This page was last modified on 25 February 2016, at 19: 59;
The saturated solubility of $\mathrm{NaCl}$ may change with the changing coupling distances in relation with the changes of temperature (Figure 11).

The radii of $\mathrm{K}$ atom and ion are much larger than that of $\mathrm{N}$ $[17,18]$. The trajectories of electron rotation appear "gourd pattern" with one end of larger sphere and other end of smaller sphere. The ellipse trajectory of electrons is more narrow and long at the $\mathrm{K}$ side than at the $\mathrm{Cl}$ side (Figure 10 lower part). The rotation centers of the system $\mathrm{KCl}$ may have different choices of its position $\left(\mathrm{C}^{\prime}, \mathrm{C}^{\prime \prime}, \mathrm{C}^{\prime \prime}\right.$, etc.). The ellipse trajectories of electrons around atom $\mathrm{K}$ and $\mathrm{Cl}$ tend to the circles under the thermal dynamics of molecules $\mathrm{K}, \mathrm{Cl}$ itself, and squeeze with water molecules, when temperature increase and tend to $100^{\circ} \mathrm{C}$. The radios (and the volume) of the $\mathrm{KCl}$ system around the mass center tend to decrease in relation with increase of temperature. Both the electron trajectories around the atoms of $\mathrm{K}$ and $\mathrm{C}$ are circles and tangency at the center of the system and the total trajectory tend to pattern of " $\infty$ ", with the radius of $0.175 \mathrm{~nm}$ (Figure 10). The specific volume of saturated solution is 129.4 $\mathrm{cm}^{3} \cdot \mathrm{g}^{-1}$ (Table 5). The parameters of the number and volume of the molecules in the salts may be calculated. As show in Figure 11, the saturation of $\mathrm{NaCl}$ tardily increase with the increase of temperature, but the density of the saturated solution of $\mathrm{NaCl}$ decrease with the increase of temperature. The volumes of the molecule $\mathrm{NaCl}$ less vary with the 
temperature variation. Both the saturation and the density of the saturated solution of $\mathrm{KCl}$ rapidly increase with the increase of temperature. The sphere volume of the molecule/ ion of $\mathrm{KCl}$ decreases with the increase of temperature. There are big differences between the salts of $\mathrm{NaCl}$ and $\mathrm{KCl}$. These are related with the specific structure (ZHTVS frame with free molecules) of liquid water (Table 5).

Table 5. Calculation samples for saturated solution of $\mathrm{NaCl}$ and $\mathrm{KCl}$.

\begin{tabular}{llll}
\hline $\mathbf{( + / )}, \mathbf{n m}$ & $\mathbf{N}+$ & $\mathbf{C l}$ & $\mathbf{K}+$ \\
\hline Radii & 0.116 & 0.167 & 0.152 \\
Neutral atom & 0.154 & 0.099 & 0.196 \\
\hline
\end{tabular}

\begin{tabular}{|c|c|c|c|c|c|c|c|c|c|c|}
\hline $\begin{array}{l}\text { Satu- } \\
\text { ration }\end{array}$ & $\begin{array}{l}\text { +Water } \\
\text { 100g }\end{array}$ & $\begin{array}{l}\text { Density, } \\
\mathrm{g} / \mathrm{cm}^{3}\end{array}$ & $\mathbf{I}, \mathbf{n m}$ & II, nm & III, $\mathbf{n m}^{3}$ & IV & $\mathbf{V}$ & VI & VII & VIII \\
\hline $\mathrm{NaCl}_{0^{\circ} \mathrm{C}}$ & 135.7 & 1.172 & 0.126 & 0.349 & 0.1776 & 65.3498 & 47.1046 & 112.450 & 112.334 & 0.107 \\
\hline $\mathrm{KCl}_{10^{\circ} \mathrm{C}}$ & 131.0 & 1.1653 & 0.208 & 0.397 & 0.2762 & 61.5799 & 47.1046 & 112.417 & 112.737 & -0.284 \\
\hline \multicolumn{3}{|c|}{ Saturate in $100 \mathrm{~g}$ water at $100^{\circ} \mathrm{C}$} & & II & III & IV & $\mathbf{V}$ & VI & VII & VIII \\
\hline \multicolumn{2}{|c|}{$\mathrm{NaCl}, 139.8$} & \multicolumn{2}{|c|}{1.1676} & 0.349 & 0.1776 & 72.8550 & 47.1046 & 119.7328 & 119.9596 & -0.1894 \\
\hline \multicolumn{2}{|c|}{$\mathrm{KCl}, 156.7$} & \multicolumn{2}{|c|}{1.2105} & 0.397 & 0.2762 & 82.2570 & 47.1046 & 129.4506 & 129.3616 & 0.0688 \\
\hline
\end{tabular}

I: Modification distances for rotation center of the $\mathrm{Na}^{+} / \mathrm{Cl}^{-}(\mathrm{K}+/ \mathrm{Cl}-)$ Molecule- Ion Systems dissolved in water (MIS in short) caused by difference between $+/-$ ion radii and atomic weights; II: Radii of the MIS, with which the system may rotate round its moment center, nm; III: Volume of MIS, nm ${ }^{3}$; IV: Total volume of MIS in the saturation liquid, $\mathrm{nm}^{3}$; V: Total water volume, $\mathrm{nm}^{3}$; VI: Observed volume of saturated liquid, $\mathrm{cm}^{3}$; VII: Calculated volume of saturated liquid, $\mathrm{cm}^{3}$; VIII: Error, \%;

The rapid increase of the saturated solubility of saccharose and other organic substances may be also related with the changes of trajectories patterns from the ellipsoid in low temperature to sphere in high temperature, caused by the compress effect of the water frame and interactions among the molecules in liquid water.

\section{Some Observed Data on Liquid Water/ Water Ice Crystal Structure}

There was some data observed and calculated by certain models published $[19,20,21]$. The microscopic picture of mono-crystals of water ice (Figure 12) shows the hexagonal structure, which is similar to this paper's model (Figure 4). The X-ray scattering curves for liquid water/ water ice and the calculated by pyramid model show their uniformity (Figure 13; 14.). In the paper titled "The crystal structure of ice at low temperatures", the observed data noted "that the condensing surface was maintained above -80 , the ice crystallized in a close-packed hexagonal structure, with the dimensions of the unit cell as follows: $\mathrm{c}=7.32 \mathrm{~A}, \mathrm{a}=4.46 \mathrm{~A}$ " [23]. These data is close (a little less than that of observed under $-80^{\circ} \mathrm{C}$ ) to the data of this paper's model: the distance between two parallel edges and the length of the edge of the hexagonal structure is $\mathrm{c}^{*}=0.83168 \mathrm{~nm}=8.32 \mathrm{~A}, \mathrm{a}^{*}=0.48017 \mathrm{~nm}=4.80 \mathrm{~A}$, separately.

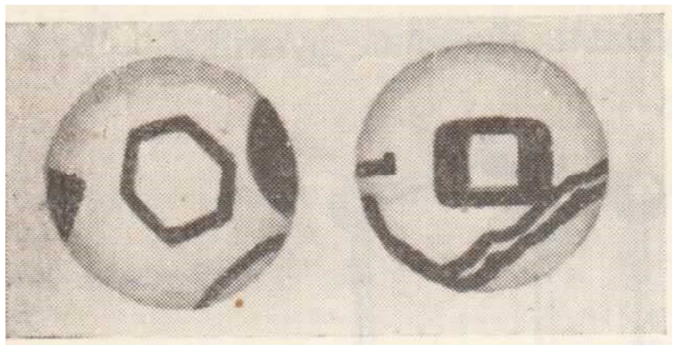

Figure 12. Microscopic picture of mono crystal of water ice [19].

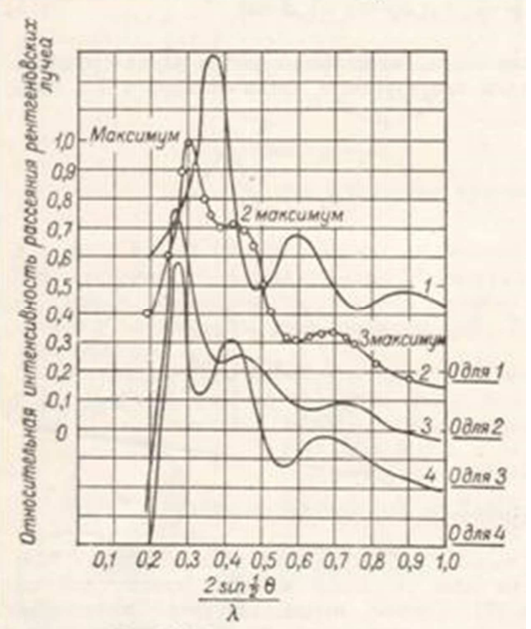

Figure 13. X-ray scattering curves for water. 1. Calculated by some close packing model. 2. Observed for water. 3. Calculated by pyramid model. 4. Observed for water ice curve, which is similar with the pyramid model [20].

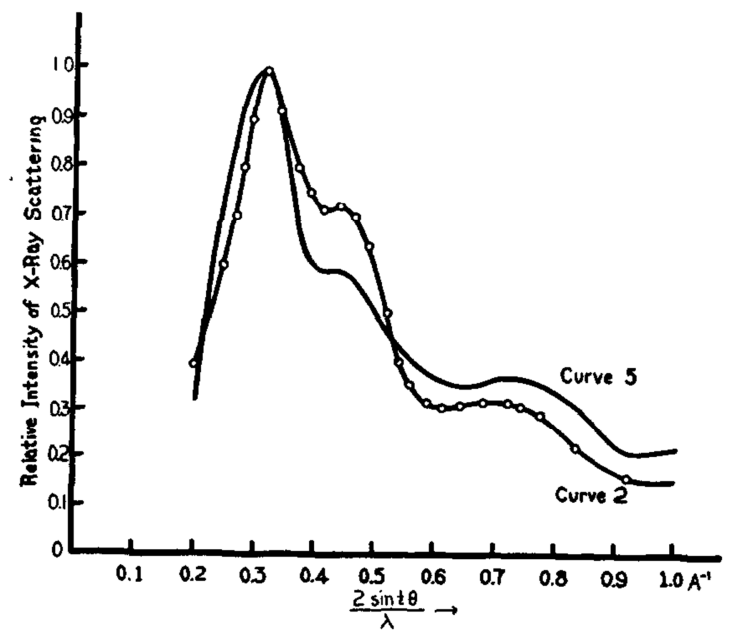

Figure 14. X-ray scattering curves for water. Curve 2-xperimental; 5-theoretical curve for quartz-like water modified by some close packing [21]. 


\section{Conclusion}

Water is one of the most important elements, which support earth ecosystem and human subsist. Its various specific characteristics of water guarantee the sustainable development earth ecosystem. These specific characteristics are strongly related with the structure of water. But "What is the structure of water?" is still one of the most challenging 125 scientific issues in the world, which is summarized and published by SCIENCE at its 125 Anniversary in 1 July 2005 [1].

1. An equilateral triangle pyramid (ETP) model with 4 equilateral triangle planes and 6 equi-edges of 0.48017 $\mathrm{nm}$ for water was presented in this paper. The volume of water molecule is $v=0.013047 \mathrm{~nm}^{3}$, which is 31.8 times more than that of inner self-similar core of H-O-H atom system. The water pyramid has 2 "+" and 2 "." endpoints and possesses obvious electric dipole moment (Figure 2). The “+”endpoint may attract “-” endpoint of another molecule in distance of about $\leq 0.27 \mathrm{~nm}$.

2. Therefore, at the 4 endpoints of a water molecule may couple 4 other molecules according to the electric "+" "_" attraction principle (endpoints and electricity are oppositely directing and planes of pyramids are parallel). This is a structure with equal possibility of distribution. In any plane (there are 4 planes of a pyramid) there are a series of hexagons- vacancy separated/ jointed by water molecules. This construction in three dimensional space is a Zigzag Hexagon Tunnel-vacancy System of solid water ice (ZHTVS model-constructed by ETP model of water molecule) (Figure 4).

3. Because the possibilities for coupling the water molecules in the common plan (there are 3 endpoints) and in the vertical to the plane (1 endpoint) is quite different, so the desublimation in a plane has $3^{\mathrm{n}}$ times more possibility than in vertical to the plane direction, especially in low air temperature and humidity conditions and may has "sheet model" form of snowflake, which has the self-similarity with the hexagon-sexangle-six needle forms (Figure 5).

4. Because there is the possibility of $1 / 11$, when 2 electrons may arrive one "-" endpoint at the same time; so except keep attracting the primary "frame molecule", there may attract an additional molecule as "free molecule" in the cage (if the temperature is over $0^{\circ} \mathrm{C}$, a part of the water molecule may has sufficient energy for extricating itself from the frame). Some "frame molecules" become the "free molecules" lead to decrease volume of solid water (water ice). The rigid ice becomes "melted" and "soften" as liquid water, decreasing its density. Till $4^{\circ} \mathrm{C}$, all $1 / 11$ possible frame molecules may become free molecules in the frame, the density of water ice is that of liquid water of $11 / 12=0.916667$, which is close accord with the recent measured data. The facts that the melting temperature of heavy water ice $\left(\mathrm{D}_{2} \mathrm{O}\right)$ is $3.82^{\circ} \mathrm{C}$, and the characteristics of subcooled water, indicate the reasonability of the proposed structure model of water.
The liquid water may adapt its pattern to any surrounding solid boundary during time scale of fs. The porosity ratio of liquid water under temperature of $4-100^{\circ} \mathrm{C}$ is 2.28 .

5 . The scale and the parameters of the water molecule, its stereoscopic electric dipole moment, the density, the thermal and electric conductivity, of water, and the coupling distance between molecules in relation with temperature are discussed and numerical simulated in this paper. The density of water under high temperature and pressure was observed as high as $2.16 \mathrm{~g} / \mathrm{cm}^{3}$ [10], which is lower, but approaches theoretical ratio of vacancy/molecule occupancy of 2.28 .

6. Many gases (take $\mathrm{O}_{2}$ and $\mathrm{H}_{2} \mathrm{~S}$ as samples), inorganic salts (take $\mathrm{NaCl}$ and $\mathrm{KCl}$ as samples), and organic substances may dissolve in water. Their different characters of saturate solution in relation with the temperature variation can be explained and numerical simulated with good coincidence by this water structure model. The process of experiment of solution $\mathrm{NaCl}$ into water was described in detail. When the crystals $\mathrm{NaCl}$ was dissolving into the liquid water, there appear a lot of air bubbles in the tube, the total volume of salt water decreases, the salt water will increase volume on $1 / 11$ that of original fresh water after freeze. All these indicate that the existence of ZHTVS model is a real fact of high possibility. The existence of free water molecules, being electric attracted with the frame water molecules in the cage of water frame structure is the necessary and sufficient condition for existence of liquid state of water. There was some data observed and calculated by certain models published [19, 20, 21]. The microscopic pictures of mono-crystals of water ice (Figures 12, 13, 14) show the hexagonal structure, which is similar to this paper's model.

7. The macroscopic phenomena of liquid water, being strongly related with its micro-structure are the basic theoretical and applied studies in earth sciences. Water mass with different physical, chemical, biological, ecological characteristics constructed by water molecules in number density of about $3.34 \times 10^{22}$ particles: $\mathrm{g}^{-1}$ and all the dissolved, suspended, floating substances in it and as boundary conditions and interactions with other solid, liquid and gaseous substances, etc. come into a complex macro-system, supporting the Earth ecosystem. The surface liquid water in boundary with atmospheric air has special characteristics and need to be studied in detail. The liquid water skin structure and its influence on atmospheric electric fields have been published [22]. Some applications related with structure of water were discussed [23]. The related issues of negative ions in atmosphere and earth magnetism would be discussed in future.

\section{Acknowledgements}

We are grateful for the beneficial discussion on this topic 
with Professors Rongsheng WU, Shanzhe KE, ZhihaoYU of Nanjing University, P. R. China, and for the supporting in labs of NIGLAS, and Nanjing Normal University.

\section{References}

[1] Kenned, D and C. Norman, What Don't We Know? http://www. sciencemag.org/sciext/125th/; 1 July 2005: $125^{\text {th }}$ Anniversary. Vol. 309, Issue 5731, pp. 75.

[2] Horne R. A. Marine Chemistry, The Structure of Water and the Chemistry of the Hydrosphere, Wiley Interscience, 1969.

[3] Tokyo Astronomical Observatory, Ed. By, Science Year Book, $60^{\text {th }}$ Edition, 1987.

[4] Yakolef, K. P. Ed. Handbook of Physics and Technology, Volume 1. Mathematics and Physics, Physic-Math Press. Moscow, 1960.

[5] Van der Waals radius, From Wikipedia, the free encyclopedia; https://en.wikipedia.org/wiki/Van_der_Waals_redius.

[6] HU shenzhi, ZHOU Zhaohui, CAI Qiru, Mean van Der Waal's radii, of atoms in crystals. Acta Phys.-Chim. Sin., 2003, 19 (11): 1073-1077.

[7] SA Clough, Y Beers, GP Klein, LS Rothman. Dipole moment of water from Stark measurements of $\mathrm{H}_{2} \mathrm{O}, \mathrm{HDO}$, and $\mathrm{D}_{2} \mathrm{O}$, Journal of Chemical Physics, 1973, 59 (5): 2254-2259.

[8] Dame Kathleen Lonsdale, The Structure of Ice, - Proceedings of the Royal Society of A, Mathematical, Physical \& Engineering Sciences, 1958 - rspa.royalsocietypublishing.org.

[9] W. F. Giauque, J. W. Stout, J. Am. Chem. Soc., 1936, 58 (7), pp 1144-1150; 7 Publication Date: July 1936; (Proceedings of the Royal Society A: Mathematical, Physical \& Enciences).

[10] ZHAN Zhenbin, CHEN Zhengdong, LIU Leansheng, et al, Theory anf Application of Ocenology-Oceanological Chemistry of Chinese Costal Waters, Oceanological Press, 1999. Beijing.

[11] Freezing-Wikipedia, the free encyclopedia.html; https://en.wikipedia.org/wiki/Freezing\#Supercooling; $-40^{\circ} \mathrm{C},-7$ $0^{\circ} \mathrm{C}$.
[12] Dorsey, N. E., Properties of Ordinary Water-Substance, Reinhold, New York, 1940.

[13] Kompanets, A. S. Theoretical Physics, People Education Press. 1961, Beijing.

[14] Electrical resistivity and conductivity; https://en.wikipedia.org/wiki/Electrical_resistivity and condu ctivity.

[15] Dean, John A. Lange's Handbook of Chemistry, $11^{\text {th }}$ Edition, 1973.

[16] V. L. Thurmond, R. W. Potter II-, and M. A. Clynne. The Densities of Saturated Solutions of $\mathrm{NaCl}$ and $\mathrm{KCl}$ from $10^{\circ}$ to $105^{\circ} \mathrm{C}$, UNITED STATES DEPARTMENT OF THE INTERIOR GEOLOGICAL SURVEY, Open File Report, 1984 http://pubs.usgs.gov/of/1984/0253/report.pdf; Ionic radius; https://en.wikipedia.org/wiki/Ionic_radius.

[17] Atomic radii of the elements (data page), https://en.wikipedia.org/wiki/Atomic_radii_of_the_elements_( data_page).

[18] Ionic radius, From Wikipedia, the free encyclopedia, https://en.wikipedia.org/wiki/Ionic_radius; (Redirected from Ionic Radius).

[19] Shuleikin, V. V. Brief Oceanography, Hydrometeorology Press, Moscow-Leningrad, 1959. (Photo for Mono-crystal of ice)

[20] Bernal I. D. and Fowler R. H. J. of Chemical Physics, 1933, V. 1: 518.

[21] Burton E. F. and W. F. Oliver, Proc. R. Soc. Lond. A 1935 153, 166-172, doi: 10.1098/ rspa. 1935.0229.

[22] PU Peimin, PU Jiangping, ZHU Zhengbin, Liquid water skin structure \& its influence on atmospheric electric fields, SCIREA, Journal of Geosciences, 2017, 2 (2): 39-55. (http://www.scirea.org/journal/PaperInformation?JournalID=1 7000\&PaperID=334). (http://article.scirea.org/pdf/17010.pdf).

[23] PU, Peimin, PU, Jiangping. Optimized structure of aqua-eco-floating island systems and its applications for suppressing evaporation from water surface, et cetera. 《The rise of China as a powerful country with talents $\rangle,$ Ed. in Chief: Zen Ronglu. 2018: 126-132. Footnote, f. n. 2: https://en.wikipedia.org/wiki/Properties_of_water. 